This paper is a post-print of a paper submitted to and accepted for publication in IEEE Journal of Emerging and Selected Topics in Power Electronics and is subject to Institution of Electrical and Electronic Engineering Copyright. The copy of record is available at IEEE Xplore Digital Library

\title{
An Improved DC fault Protection Algorithm for MMC HVDC Grids based on Modal Domain Analysis
}

\author{
Saizhao Yang, Wang Xiang, Member, IEEE, Rui Li, Xiaojun Lu, Member, IEEE, Wenping Zuo, Jinyu Wen, Member, IEEE
}

\begin{abstract}
To detect the DC faults for MMC based DC grids using overhead line transmission, many protection methods in phase-domain have been proposed. These existing protection methods suffer from incomplete function, weak theoretical basis and sensitivity to fault resistance and noise disturbance. To overcome these shortcomings, this paper proposes an improved DC fault protection algorithm using the modal-domain approach for the MMC based overhead DC grids, which decouples interaction between positive and negative poles and mitigates the strong frequency-dependency of the characteristic impedance in phase-domain. The DC fault equivalent circuits are established in modal-domain and the fault characteristics during the initial stage are analysed. Based on the modal-domain analysis, the line-mode reactor voltage which combines fault characteristics of negative and positive reactor voltages, is employed to identify the internal faults. The zero-mode reactor voltage which enlarges the differences between faulty and healthy poles, is employed to select the faulted pole. This method is robust to fault resistance and noise with high detection speed. In addition, it is not affected by power reversal, AC faults and DCCB operation, which are validated and evaluated by simulations in PSCAD/EMTDC.
\end{abstract}

Index Terms - MMC-HVDC grids, DC fault detection, modal-domain analysis, phase-modal transformation, anti-noise.

\section{INTRODUCTION}

The modular multilevel converter (MMC) based DC grids have been a preferred solution to integrate bulk renewable energy over long distance [1]-[3]. Recently, the State Grid Corporation of China (SGCC) is constructing the $\pm 500 \mathrm{kV}$ Zhangbei DC grid, which transmits large-scale wind power using the overhead lines (OHL) [4]. Comparing with the point-to-point HVDC transmission systems, each converter of DC grids will feed current to the fault point during DC faults, leading to higher fault current [5]. To avoid damage of power electronic devices and guarantee reliable power supply for healthy parts, DC circuit breakers (DCCB) are implemented to isolate the faulted lines [6]. Taking Zhangbei project as an example, the DCCBs are required to interrupt $25 \mathrm{kA}$ DC fault current within 6ms [7], which puts forward stringent speed requirements for the DC fault protection algorithm.

With regard to the protection design of MMC based DC grids, the traveling-wave (TW) methods in time-domain are mostly employed to identify internal and external faults, such

This work is sponsored by the National Natural Science Foundation of China (U1766211 and 51807071). (Corresponding author: Wang Xiang)

S. Yang, X. Lu, W. Zuo, J. Wen are with the State Key Laboratory of Advanced Electromagnetic Engineering and Technology, Huazhong University of Science and Technology, Wuhan 430074, China. (e-mail: saizhaoyang@foxmail.com, luxiaojun@hust.edu.cn, radio.zuo@foxmail. com, jinyu.wen@hust.edu.cn).

W. Xiang and R. Li are with the Department of Electronic and Electrical Engineering, University of Strathclyde, Glasgow, G1 1XW, UK (email: xiangwang1003@foxmail.com,rui.li@strath.ac.uk) as the rate of change of current (ROCOC) [8], the rate of change of voltage (ROCOV) [9], the wave peak [10] methods and so on. As pointed out in [11], the amplitudes of the traveling-waves will attenuate under large fault resistance, particularly for pole-to-ground (PTG) faults. Besides, the initial wave front and wave peak are difficult to be detected encountering noise disturbance. To improve the robustness to fault resistance, the wavelet transform (WT) in the time-frequency domain can be adopted to extract the high-frequency components [7][11].

When a DC fault occurs, the sharp wave front of traveling wave induced from the fault point will be smoothed at the current-limiting reactors (CLR). Considering this boundary effect, some boundary protection approaches taking advantage of DC current-limiting reactors are proposed. Reference [7] proposes a transient voltage based DC fault detection method on the basis of the high-frequency characteristics difference between the converter and line sides of CLRs. References [12] and [13] propose protection methods based on DC reactor voltage change rate (RVCR) and DC reactor voltage of faulted pole (RVOFP) respectively. The voltages across the CLRs are employed as an indicator.

According to [14], the aforementioned protection methods can be classified into phase-domain methods. The advantages and disadvantages of them are listed in Table 1 (some methods may belong to multiple categories). As can be seen, the traveling wave methods are sensitive to fault resistance. The WT methods may bring about additional calculation delay and burden when the decomposition layer is high. The DC reactor based methods suffer from incomplete functions. In addition, due to the strong frequency-dependency of the characteristic impedance in overhead lines, these phase-domain methods are difficult to conduct a comprehensive fault analysis, especially under asymmetrical PTG faults, which makes them lack of theoretical basis.

To address the shortcomings of phase-domain methods, the phase-modal transformation (PMT) is employed to decouple the dependency of the poles of transmission lines and the fault analysis under modal-domain is carried out to design the protection schemes. In [15][16], modal-domain is selected to improve the performance of fault detection algorithms, such as the capability of the faulted pole selection and the robustness to fault resistance. In [15], the line-mode backward travelling-wave voltage associated with WT modulus maximum (WTMM) is adopted. However, a sampling frequency as high as $1 \mathrm{MHz}$ is required. A lifting WT based protection is proposed in [16]. The line-mode travelling-wave voltage with four decomposition layers is calculated to detect the arrival of wave fronts accurately. However, due to the four decomposition layers of WT, the time delay and computational burden is high. The analysis of these existing 
This paper is a post-print of a paper submitted to and accepted for publication in IEEE Journal of Emerging and Selected Topics in Power Electronics and is subject to Institution of Electrical and Electronic Engineering Copyright. The copy of record is available at IEEE Xplore Digital Library

modal-domain methods is also concluded in Table 1.

To overcome the challenges of the aforementioned methods, a fast and reliable protection scheme based on modal-domain analysis is proposed for MMC based DC grids using overhead line transmission. The contributions of the proposed method are as follows:

1) The PTG and PTP fault analysis under modal-domain are conducted respectively, which mitigates the dependency of positive and negative poles of overhead lines in phase-domain and improves the capability of the faulted pole selection and endurance to fault resistance. Compared with the phase-domain methods, this paper provides a solid theoretical foundation for the PTG faults.

2) The modal components of reactor voltages are selected

Table 1 Overall comparison of typical protection schemes and the improvement in the proposed method

\begin{tabular}{|c|c|c|c|}
\hline \multicolumn{2}{|c|}{ Protection methods } & Advantages & Disadvantages \\
\hline \multirow{3}{*}{$\begin{array}{l}\text { Phase-domain based } \\
\text { methods }\end{array}$} & $\begin{array}{l}\text { The traveling-wave methods based } \\
\text { on time-domain analysis } \\
\text { (for instance }[8][9][10] \text { ) }\end{array}$ & $\begin{array}{l}\text { 1. Simple concept and widely } \\
\text { implemented. } \\
\text { 2. Almost no computation is } \\
\text { required. }\end{array}$ & $\begin{array}{l}\text { 1. The sharp wave front will attenuate with large } \\
\text { resistance, particularly for PTG faults. } \\
\text { 2. Difficult to detect the initial wave front and wave } \\
\text { peak under noise disturbance. }\end{array}$ \\
\hline & $\begin{array}{l}\text { The WT methods based on } \\
\text { time-frequency domain analysis } \\
\text { (for instance }[7][11])\end{array}$ & $\begin{array}{l}\text { 1. WT is employed to extract the } \\
\text { high-frequency components } \\
\text { efficiently. }\end{array}$ & $\begin{array}{l}\text { 1. High computational burden and long time delay } \\
\text { due to the cascaded filtering and multi-scale } \\
\text { decomposition [8]. } \\
\text { 2. Weakness to noise. }\end{array}$ \\
\hline & $\begin{array}{l}\text { DC reactor based methods } \\
\quad(\text { for instance }[12][13])\end{array}$ & $\begin{array}{l}\text { 1. Simple implementation and low } \\
\text { computational burden. } \\
\text { 2. Work well for faults with high } \\
\text { resistance [12] or different fault } \\
\text { types [13]. }\end{array}$ & $\begin{array}{l}\text { 1. Sensitivity to fault type or resistance. } \\
\text { 2. Lack of detailed fault characteristic analysis for } \\
\text { PTG faults. } \\
\text { 3. Impacts of noise are not discussed in detail. }\end{array}$ \\
\hline $\begin{array}{l}\text { Existing } \\
\text { modal-domain } \\
\text { based methods }\end{array}$ & $\begin{array}{l}\text { The line-mode backward voltage TW } \\
\text { based on WTMM } \\
\text { (for instance [15][16]) }\end{array}$ & $\begin{array}{l}\text { 1. WT is employed to detect arrival } \\
\text { of wave fronts accurately. } \\
\text { 2. Robustness to noise. } \\
\text { 3. Work well for faults with high } \\
\text { resistance and different fault types. }\end{array}$ & $\begin{array}{l}\text { 1. High computational burden with four } \\
\text { decomposition scales of WT. } \\
\text { 2. High sampling frequency }(1 \mathrm{MHz}) \text { is required [15]. }\end{array}$ \\
\hline \multicolumn{2}{|c|}{$\begin{array}{l}\text { Improvement in the proposed } \\
\text { modal-domain based method }\end{array}$} & \multicolumn{2}{|c|}{$\begin{array}{l}\text { 1. Endurance to fault resistance. } \\
\text { 2. Robustness to noise. } \\
\text { 3. Able to select the faulted pole. } \\
\text { 4. High speediness for fault detection. } \\
\text { 5. Low computational burden with lower sampling frequency. } \\
\text { 6. Strong theoretical basis for both PTP and PTG faults. }\end{array}$} \\
\hline
\end{tabular}

\section{EQUivalent FAULT NETWORK OF MMC BASED DC GRID UNDER MODAL-DOMAIN}

Fig. 1 shows a typical topology of half-bridge MMC based DC grid [16]. The hybrid DCCBs are implemented to interrupt the DC fault current. To suppress the rise rate of fault current, the current-limiting reactors are installed on the overhead lines (OHL) [17]. This system adopts the symmetric monopole structure and the OHL adopts the frequency-dependent model.

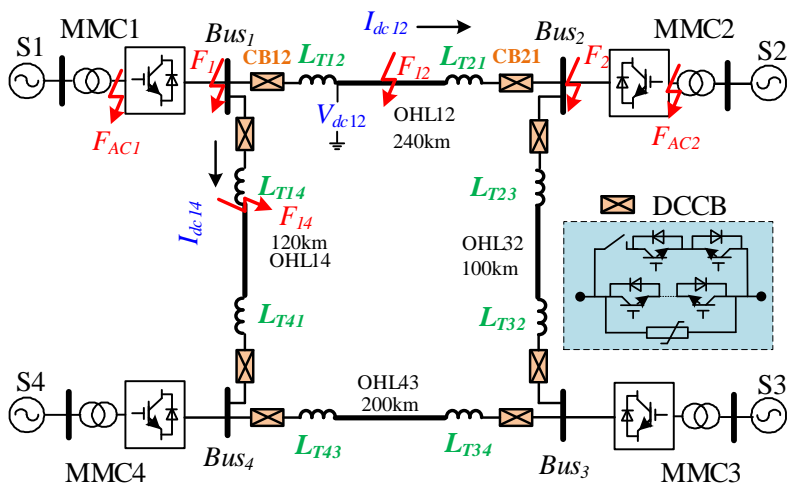

Fig. 1. The topology of MMC based DC grid. to design the fault detection algorithm. The line-mode reactor voltage is employed to identify the external and internal faults. The zero-mode reactor voltage is employed to select the faulted pole. This method can reduce the computational burden greatly compared with the WT based methods and the existing modal-domain methods.

The remainder of the paper is structured as follows. Section II derives the equivalent fault network of DC grid under modal-domain. Fault analysis under modal-domain is conducted in section III. Then, the overall protection scheme is proposed in section IV. Finally, the effectiveness and robustness of the proposed method are verified under extensive cases in section $\mathrm{V}$ and VI. 
This paper is a post-print of a paper submitted to and accepted for publication in IEEE Journal of Emerging and Selected Topics in Power Electronics and is subject to Institution of Electrical and Electronic Engineering Copyright. The copy of record is available at IEEE Xplore Digital Library

capacitor per unit length respectively. And $L_{0 m n}, R_{0 m n}$, and $M_{0 m n}$ denote the self-inductance, resistance and mutual inductance of line $m n$ per unit length respectively.

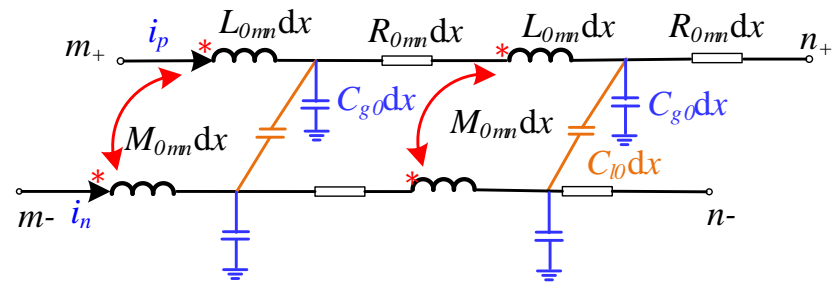

Fig. 3. The detailed distributed parameter model of overhead line.

The typical value of line capacitance (grounding capacitor and phase capacitor) and sub-module equivalent capacitance are $0.01 \mu \mathrm{F}$ and $1 \times 10^{2} \mu \mathrm{F}$ respectively [21]. Thus, the discharge current from sub-module capacitors is much larger than that of line capacitor. Hence, the line capacitor can be ignored and the OHL model is simplified to a $R L$ series circuit, as shown in Fig. 4.

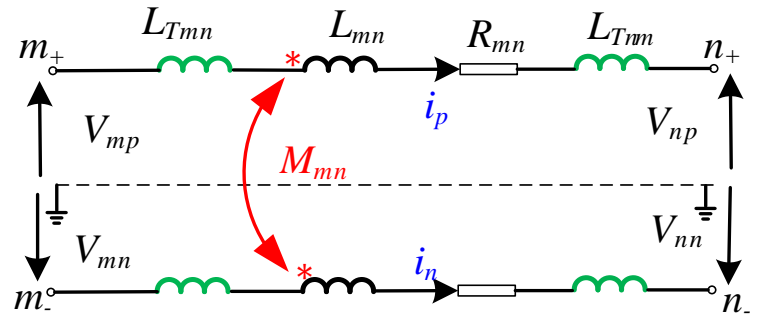

Fig. 4. The simplified equivalent model of overhead transmission line.

In Fig. $4, L_{m n}, R_{m n}$, and $M_{m n}$ denote the self-inductance, resistance and mutual inductance of line $m n$ respectively. The subscripts " $m$ " and " $n$ " represent node $m$ and node $n$; subscripts " $p$ " and " $n$ " represent positive and negative pole. According to KVL, it can be obtained:

$$
\begin{aligned}
{\left[\begin{array}{c}
V_{m p} \\
V_{m n}
\end{array}\right] } & =\left[\begin{array}{cc}
L_{T m n}+L_{m n}+L_{T n m} & M_{m n} \\
M_{m n} & L_{T m n}+L_{m n}+L_{T n m}
\end{array}\right] \frac{d}{d t}\left[\begin{array}{c}
i_{p} \\
i_{n}
\end{array}\right] \\
& +\left[\begin{array}{cc}
R_{m n} & 0 \\
0 & R_{m n}
\end{array}\right]\left[\begin{array}{l}
i_{p} \\
i_{n}
\end{array}\right]+\left[\begin{array}{c}
V_{n p} \\
V_{n n}
\end{array}\right]
\end{aligned}
$$

In order to decouple the dependency of the poles of transmission lines under PTG faults, phase-modal transformation is employed, as shown in equation (2) [22].

$$
\left[\begin{array}{l}
x_{1} \\
x_{0}
\end{array}\right]=\left[\begin{array}{cc}
1 & -1 \\
1 & 1
\end{array}\right]\left[\begin{array}{l}
x_{p} \\
x_{n}
\end{array}\right]
$$

where $x_{p}$ and $x_{n}$ represent the positive and negative pole values. $x_{0}$ and $x_{1}$ represent the zero-mode and line-mode values. Applying the phase-modal transformation to equation (3), it can be obtained:

$$
\left\{\begin{aligned}
{\left[\begin{array}{c}
V_{m 1} \\
V_{m 0}
\end{array}\right]=} & {\left[\begin{array}{cc}
L_{T m n}+L_{m n 1}+L_{T n m} & 0 \\
0 & L_{T m n}+L_{m n 0}+L_{T n m}
\end{array}\right] \frac{d}{d t}\left[\begin{array}{l}
i_{1} \\
i_{0}
\end{array}\right] } \\
+ & {\left[\begin{array}{cc}
R_{m n} & 0 \\
0 & R_{m n}
\end{array}\right]\left[\begin{array}{l}
i_{1} \\
i_{0}
\end{array}\right]+\left[\begin{array}{c}
V_{n 1} \\
V_{n 0}
\end{array}\right] } \\
& L_{m n 1}=L_{m n}-M_{m n} ; \quad L_{m n 0}=L_{m n}+M_{m n}
\end{aligned}\right.
$$

where subscripts " 1,0 " represent the line-mode and zero-mode components respectively. Equation (3) demonstrates that an asymmetric coupled equivalent network can be decomposed into two symmetric decoupled networks by the phase-modal transformation. The line-mode and zero-mode equivalent model of OHL under modal-domain are shown in Fig. 5.

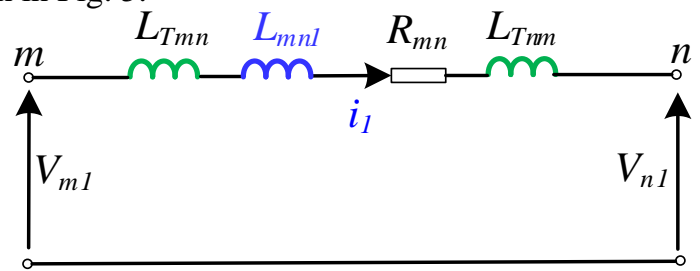

(a) Line-mode circuit

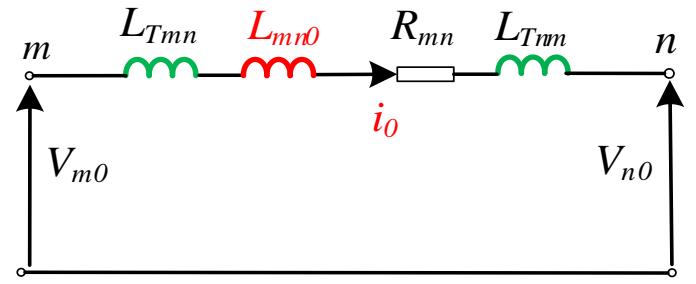

(b) Zero-mode circuit

Fig. 5. The line-mode and zero-mode circuit of overhead transmission line.

\section{Fault Network of DC Grid in Modal-domain}

Based on the equivalent models of MMC and OHL, the model of four-terminal DC grid can be obtained, as shown in Fig. 6. Suppose a fault happen at $n$ of OHL12 $\left(F_{12}\right)(0<n<1)$. During the fault wave propagation stage, the CLR and line inductance provide higher impedance characteristics, comparing with line resistances. Thus, the line resistance and arm resistance are ignored [12]. The un-faulted OHL14 and OHL23 are equivalent to two voltage sources with the voltage of $V_{14}$ and $V_{23}$, where $C_{e q 14}$ and $C_{e q 23}$ are the equivalent capacitances of the terminal of OHL14 and OHL23 respectively, as shown in Fig. 7[12]. Thus, the simplified equivalent fault network during fault initial stage can be obtained, as shown in Fig. 7(a). The line-mode and zero-mode networks under modal-domain are depicted in Fig. 7 (b) and Fig. 7 (c) respectively.

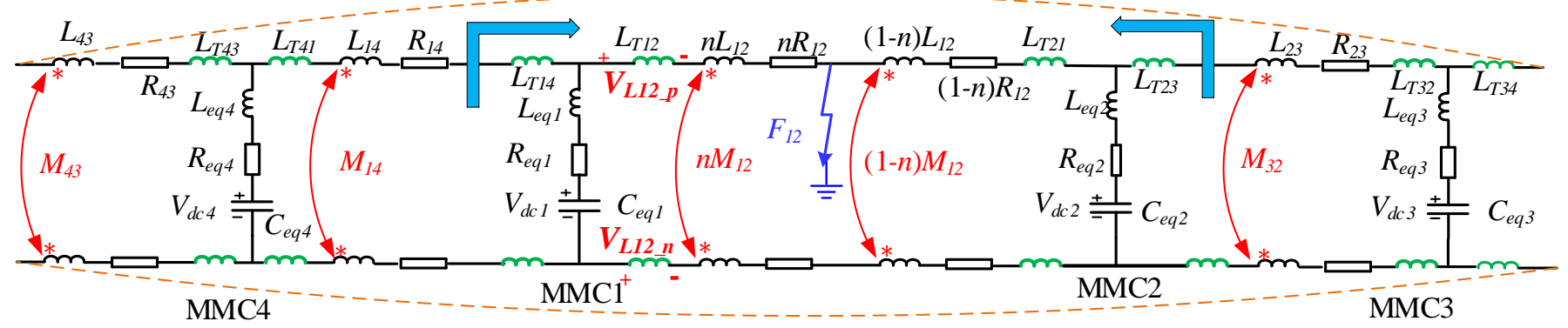

Fig. 6. The fault equivalent network of the symmetric monopole system under PTP faults. 
This paper is a post-print of a paper submitted to and accepted for publication in IEEE Journal of Emerging and Selected Topics in Power Electronics and is subject to Institution of Electrical and Electronic Engineering Copyright. The copy of record is available at IEEE Xplore Digital Library

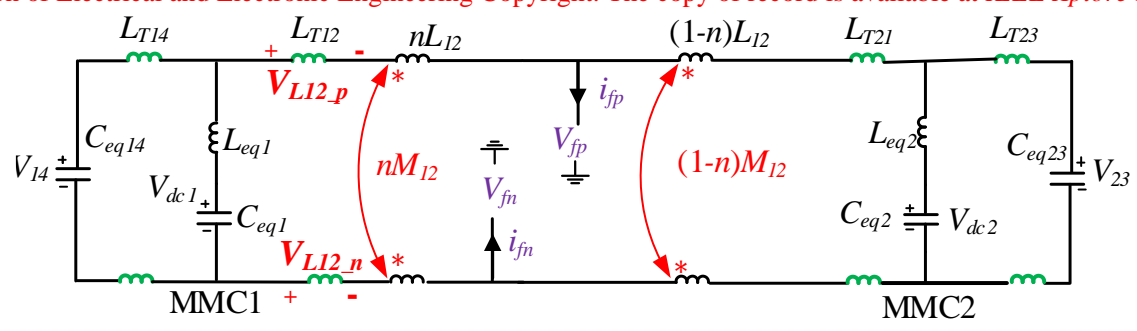

(a) Simplified system equivalent network at $F_{12}$

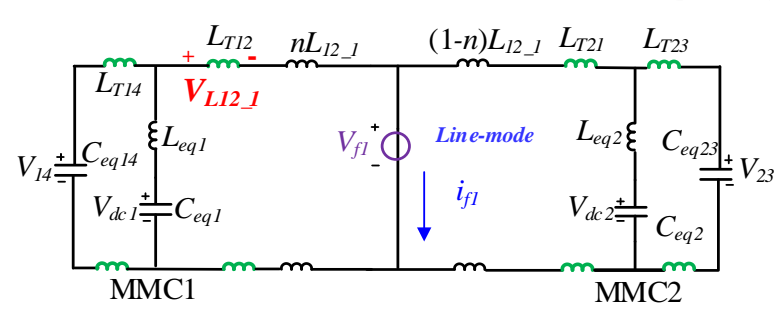

(b) Line-mode equivalent network at $F_{12}$

Fig. 7. The simplified equivalent network of system with a fault at $F_{12}$.

\section{FAULT ANALYSIS OF MMC BASED DC GRID UNDER MODAL-DOMAIN}

\section{A. PTG Fault Analysis under Modal-domain}

\section{1) Fault Analysis under Internal PTG Faults}

Taking CB12 for an example, applying a positive PTG (P-PTG) fault at $F_{12}$, the fault boundary condition is $i_{f n}=0$, $V_{f p}=0$. Based on the phase-modal transformation, the fault boundary condition can be re-written as:

$$
\left\{\begin{array}{c}
V_{f 1}+V_{f 0}=0 \\
i_{f 1}=i_{f 0}
\end{array}\right.
$$

It can be seen from the above fault boundary condition that the zero-mode network is connected with the line-mode network in series. Thus, the composite mode network under modal-domain can be obtained, as shown in Fig. 8.

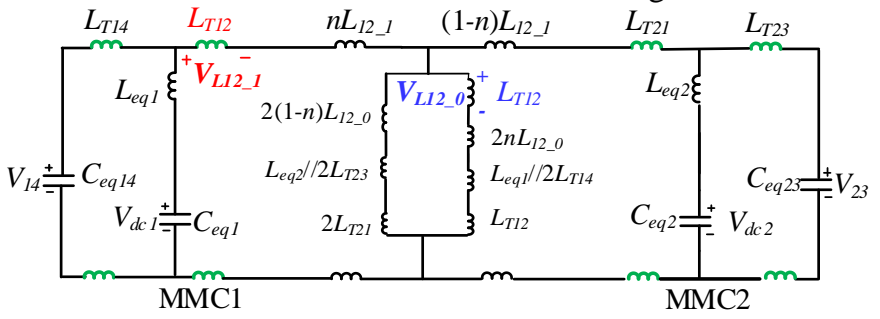

Fig. 8. The composite mode network under internal P-PTG faults.

Assuming the value of each CLR is $V_{T}$ and the instantaneous MMC DC terminal voltages at fault instant are $V_{d c n}$ (the rated DC voltage). Thus, the instantaneous values at fault instant of line-mode and zero-mode voltage across $L_{T 12}\left(V_{L L_{2}-1}^{0}\right.$ and $\left.V_{L L_{-} O}^{0}\right)$ can be calculated (the reference direction of positive and negative reactor voltage is shown in Fig. 2):

$$
\left\{\begin{aligned}
V_{L 12_{-} l}^{0} & =\frac{L_{T} V_{d c n}}{L_{1}+L_{2} / / L_{3} / / L_{4}}+\frac{-L_{T} V_{d c n}}{L_{2}+L_{1} / / L_{3} / / L_{4}} \times \frac{L_{1} / / L_{3} / / L_{4}}{L_{1}} \\
V_{L 12_{-} 0}^{0} & =\frac{L_{T} V_{d c n}}{L_{1}+L_{2} / / L_{3} / / L_{4}} \times \frac{L_{2} / / L_{3} / / L_{4}}{L_{3}} \\
& +\frac{L_{T} V_{d c n}}{L_{2}+L_{1} / / L_{3} / / L_{4}} \times \frac{L_{1} / / L_{3} / / L_{4}}{L_{3}}
\end{aligned}\right.
$$

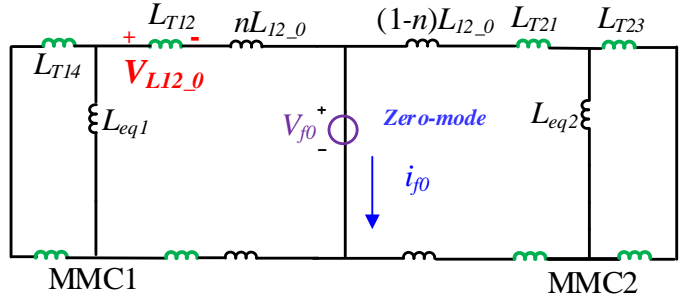

(c) Zero-mode equivalent network at $F_{12}$

$$
\left\{\begin{array}{l}
L_{1}=L_{e q 1} / / 2 L_{T}+2 L_{T}+2 n L_{12 \_} 1 \\
L_{2}=L_{e q 2} / / 2 L_{T}+2 L_{T}+2(1-n) L_{12 \_} 1 \\
L_{3}=L_{e q 1} 1 / 2 L_{T}+2 L_{T}+2 n L_{12 \_} 0 \\
L_{4}=L_{e q 2} / / 2 L_{T}+2 L_{T}+2(1-n) L_{12 \_} 0
\end{array}\right.
$$

From equations (5)-(6), it can be concluded:

a) $V_{L L_{2} I}^{0}$ is positive and large under internal P-PTG faults.

b) $V_{L L 2 \_0}^{0}$ is positive under internal P-PTG faults.

Similarly, for internal N-PTG faults, $V_{L L 2_{-} l}^{0}$ and $V_{L L_{2} 0}^{0}$ can also be calculated as:

$$
\left\{\begin{aligned}
V_{L 12_{-} 1}^{0} & =\frac{L_{T} V_{d c n}}{L_{1}+L_{2} / / L_{3} / / L_{4}}+\frac{-L_{T} V_{d c n}}{L_{2}+L_{1} / / L_{3} / / L_{4}} \times \frac{L_{I} / / L_{3} / / L_{4}}{L_{1}} \\
V_{L 12_{-} 0}^{0} & =\frac{-L_{T} V_{d c n}}{L_{1}+L_{2} / / L_{3} / / L_{4}} \times \frac{L_{2} / / L_{3} / / L_{4}}{L_{3}} \\
& +\frac{-L_{T} V_{d c n}}{L_{2}+L_{1} / / L_{3} / / L_{4}} \times \frac{L_{1} / / L_{3} / / L_{4}}{L_{3}}
\end{aligned}\right.
$$

Equation (7) indicates that $V_{L I 2 \_0}^{0}$ is negative under internal N-PTG faults.

\section{2) Fault Analysis under External PTG Faults}

Apply P-PTG faults at $F_{l}$ (backward external fault) and at $F_{2}$ (forward external fault) respectively. The composite mode networks under modal-domain at $F_{1}$ and $F_{2}$ are presented in Fig. 9.

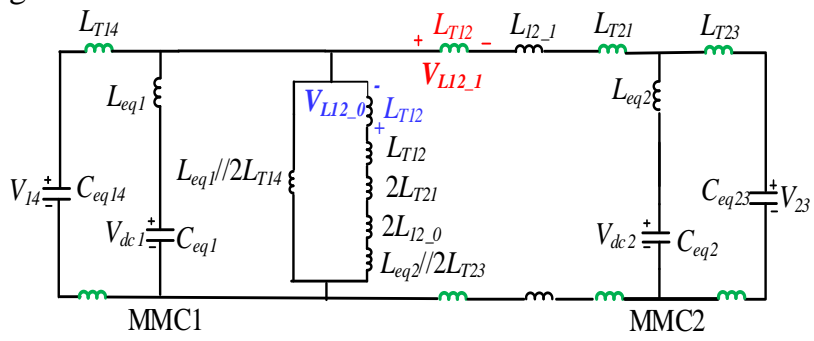

(a) The composite mode network at $F_{l}$

where the inductances $L_{1}, L_{2}, L_{3}$ and $L_{4}$ can be expressed as: 
This paper is a post-print of a paper submitted to and accepted for publication in IEEE Journal of Emerging and Selected Topics in Power Electronics and is subject to Institution of Electrical and Electronic Engineering Copyright. The copy of record is available at IEEE Xplore Digital Library

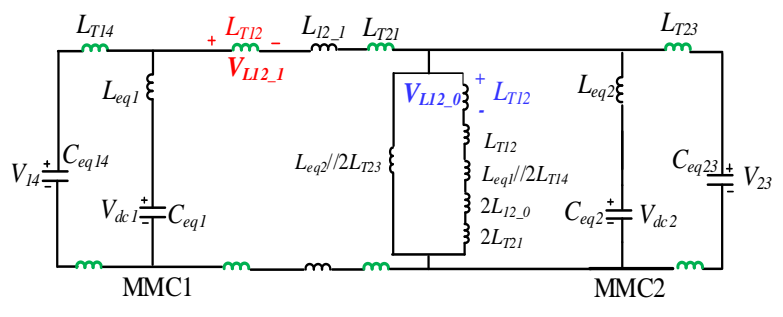

(b) The composite mode network at $F_{2}$

Fig. 9. The composite mode networks under external P-PTG faults.

For $F_{1}$ and $F_{2}, V_{L 12_{-} l}^{0}$ and $V_{L 12_{-} 0}^{0}$ can be obtained:

$$
\begin{aligned}
& \left(V_{L 12_{-}{ }_{l}}^{0}\left(F_{1}\right)=\frac{-L_{T} V_{d c n}}{L_{5}+\frac{L_{6}}{2} / / L_{7}}+\frac{L_{T} V_{d c n}}{L_{6}+L_{5} / / L_{6} / / L_{7}} \times \frac{L_{5} / / L_{6} / / L_{7}}{L_{5}}\right. \\
& V_{L 12_{-} 0}^{0}\left(F_{1}\right)=\frac{-L_{T} V_{d c n}}{L_{5}+\frac{L_{6}}{2} / / L_{7}} \times \frac{\frac{L_{6}}{2} / / L_{7}}{L_{7}} \\
& +\frac{-L_{T} V_{d c n}}{L_{6}+L_{5} / / L_{6} / / L_{7}} \times \frac{L_{5} / / L_{6} / / L_{7}}{L_{7}} \\
& \left\{V_{L 12_{-} l}^{0}\left(F_{2}\right)=\frac{L_{T} V_{d c n}}{L_{8}+\frac{L_{9}}{2} / / L_{10}}+\frac{-L_{T} V_{d c n}}{L_{9}+L_{8} / / L_{9} / / L_{10}} \times \frac{L_{8} / / L_{9} / / L_{10}}{L_{8}}\right. \\
& V_{L 12 \_0}^{0}\left(F_{2}\right)=\frac{L_{T} V_{d c n}}{L_{8}+\frac{L_{9}}{2} / / L_{10}} \times \frac{\frac{L_{9}}{2} / / L_{10}}{L_{10}} \\
& +\frac{L_{T} V_{d c n}}{L_{9}+L_{8} / / L_{9} / / L_{10}} \times \frac{L_{8} / / L_{9} / / L_{10}}{L_{10}}
\end{aligned}
$$

where the inductances $L_{5}-L_{8}$ can be expressed as:

$$
\left\{\begin{array}{l}
L_{5}=L_{e q 2} / / 2 L_{T}+4 L_{T}+2 L_{12_{-} 1} \\
L_{6}=L_{e q 1} / / 2 L_{T} \\
L_{7}=L_{e q 1} / / 2 L_{T}+4 L_{T}+2 L_{12_{-} 0} \\
L_{8}=L_{e q 1} / / 2 L_{T}+4 L_{T}+2 L_{12_{-} 1} \\
L_{9}=L_{e q 2} / / 2 L_{T} \\
L_{10}=L_{e q 1} / / 2 L_{T}+4 L_{T}+2 L_{12 \_} 0
\end{array}\right.
$$

From equations (5)-(9), it can be concluded:

a) $V_{L 1_{2} I}^{0}$ under backward external fault $\left(F_{1}\right)$ is negative while $V_{L 12 \_I}^{0}$ under forward external fault $\left(F_{2}\right)$ is positive.

b) $V_{L 12_{1} I}^{0}$ under internal PTG faults $\left(F_{12}\right)$ is larger than that under internal PTG faults $\left(F_{2}\right)$.

\section{B. PTP Fault Analysis under Modal-domain}

For PTP faults, the fault boundary condition is $V_{f n}=V_{f p}$, $i_{f p}+i_{f n}=0$. Using the phase-modal transformation, it can be re-written as:

$$
\left\{\begin{array}{l}
V_{f 1}=0 \\
i_{f 0}=0
\end{array}\right.
$$

Based on the above fault boundary condition, the composite mode network under internal PTP faults can be obtained, as shown in Fig. 10.

$V_{L 12_{\_} I}^{0}$ and $V_{L 12_{-} o}^{0}$ under internal PTP faults are:

$$
\left\{\begin{array}{l}
V_{L 12_{-} l}^{O}=\frac{L_{T} V_{d c n}}{L_{l}} \\
V_{L 12_{-} 0}^{O}=0
\end{array}\right.
$$

Equation (11) indicates that the $V_{L 12_{-} 0}^{0}$ is equal to zero under internal PTP faults. For external PTP faults, such as $F_{1}$ and $F_{2}$, $V_{L 12_{-} I}^{0}$ can also be calculated by the composite mode network. The conclusion can be obtained:

a) $V_{L 12_{-} I}^{0}$ under backward external fault $\left(F_{l}\right)$ is negative while $V_{L 12_{1} I}^{0}$ under forward external fault $\left(F_{2}\right)$ is positive.

b) Due to the boundary effect of CLR on the change rate of fault current, the amplitude of $V_{L 12_{-} I}^{0}$ under $F_{2}$ is smaller than that of $V_{L 12_{-} I}^{0}$ under $F_{12}$.

\begin{tabular}{|c|c|c|c|}
\hline \multirow{2}{*}{\multicolumn{2}{|c|}{ Fault position }} & \multicolumn{2}{|c|}{$V_{\text {Lnn_I }}^{0}$} \\
\hline & & Polarity & Amplitude \\
\hline \multicolumn{2}{|c|}{ internal faults } & Positive & Large \\
\hline \multirow{2}{*}{$\begin{array}{c}\text { external } \\
\text { faults }\end{array}$} & reverse & Negative & 1 \\
\hline & forward & Positive & Small \\
\hline
\end{tabular}

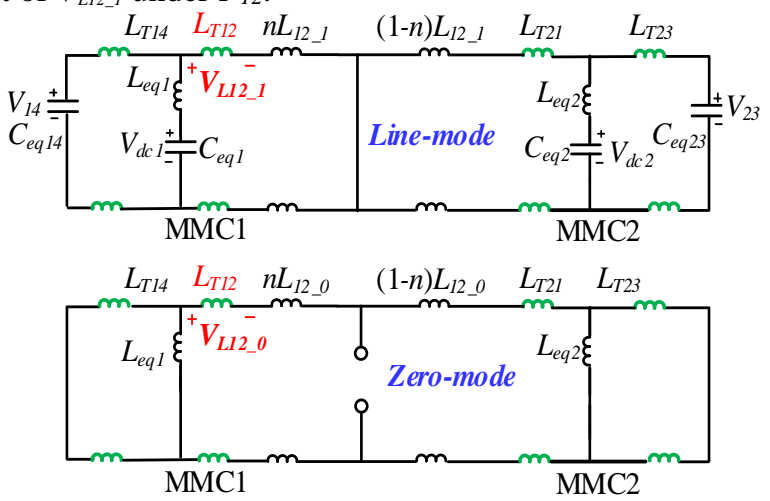

Fig. 10. The composite mode network under internal PTP faults.

\section{The OVERALl PROTECTION SCHEME BASED ON LINE-MODE AND ZERO-MODE REACTOR VOLTAGE}

\section{A. Fault Detection based on Line-mode Reactor Voltage}

Based on above modal-domain analysis, the characteristics of $V_{L m n_{-} I}^{0}$ under different faults can be obtained, as shown in Table 2 .

During fault initial stage (within $0.5 \mathrm{~ms}$ subsequent to DC faults), though voltages of sub-module capacitors decrease, line-mode reactor voltages under backward external faults are always negative but positive under forward faults. Meanwhile, line-mode reactor voltages under forward external faults are always smaller than those under internal faults, due to the boundary effect of CLR. Thus, the fault detection criterion for relay $\mathrm{CB} m n$ can be designed using the line-mode reactor voltage of line $m n\left(V_{L m n_{-} 1}\right)$ :

$$
V_{\text {Lmn_l }_{-}}>V_{\text {set }}
$$

where $V_{\text {set }}$ is the threshold for fault detection. As can be seen from equation (2), the line-mode reactor voltage combines the fault characteristics of negative and positive reactor voltages. For PTG faults, negative and positive reactor voltages under internal faults are both larger than those under external faults. Thus, line-mode reactor voltage enlarges the differences between internal and external faults, therefore improving the robustness for fault detection.

\section{B. Faulted Pole Selection based on Zero-mode Reactor Voltage}

Table 3 represents the characteristics of voltage $V_{L 12_{2} 0}^{0}$ based on modal-domain analysis for internal faults. As can be seen, 
This paper is a post-print of a paper submitted to and accepted for publication in IEEE Journal of Emerging and Selected Topics in Power Electronics and is subject to Institution of Electrical and Electronic Engineering Copyright. The copy of record is available at IEEE Xplore Digital Library

the polarity of $V_{L 12 \_0}^{0}$ for each fault type is unique and it will remain constant during fault initial stage. Thus, the faulted pole selection criterion for relay $\mathrm{CB} m n$ can be designed using the zero-mode reactor voltage of line $m n\left(V_{L m n_{-} 0}\right)$ :

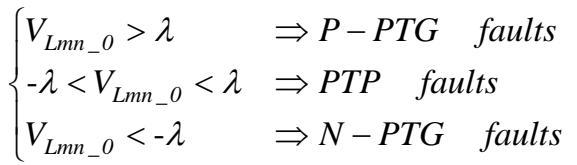

where $\lambda$ is a positive coefficient and the specified value can be obtained by the simulations.

\begin{tabular}{|c|c|c|}
\hline \multirow{2}{*}{ Fault type } & \multicolumn{2}{|l|}{$V_{L I 2_{-} O}^{0}$} \\
\hline & Amplitude & Polarity \\
\hline PTP faults & 0 & I \\
\hline P-PTG faults & $\begin{array}{l}\frac{L_{T} V_{\mathrm{dcn}}}{L_{1}+L_{2} / / L_{3} / / L_{4}} \times \frac{L_{2} / / L_{3} / / L_{4}}{L_{3}} \\
+\frac{L_{T} V_{\mathrm{dcn}}}{L_{2}+L_{1} / / L_{3} / / L_{4}} \times \frac{L_{1} / / L_{3} / / L_{4}}{L_{3}}\end{array}$ & positive \\
\hline N-PTG faults & $\begin{array}{l}\frac{-L_{T} V_{\mathrm{dcn}}}{L_{1}+L_{2} / / L_{3} / / L_{4}} \times \frac{L_{2} / / L_{3} / / L_{4}}{L_{3}} \\
+\frac{-L_{T} V_{\mathrm{dcn}}}{L_{2}+L_{1} / / L_{3} / / L_{4}} \times \frac{L_{1} / / L_{3} / / L_{4}}{L_{3}}\end{array}$ & negative \\
\hline
\end{tabular}

\section{The Modified Criteria with Anti-Noise Capability}

Noise is an interference source signal generated from the equipment or system. Signal noise ratio (SNR) is commonly employed to represent the relationship between original signal and noise signal:

$$
S N R=10 \lg \frac{P_{s}}{P_{\text {noise }}}(\mathrm{db})
$$

where $P_{s}$ is the power of original signal and $P_{\text {noise }}$ is the power of noise.

For DC grid system shown in Fig. 1, the waveform of DC voltage $V_{d c 12}$ with $20 \mathrm{db}$ noise is shown in Fig. 11.

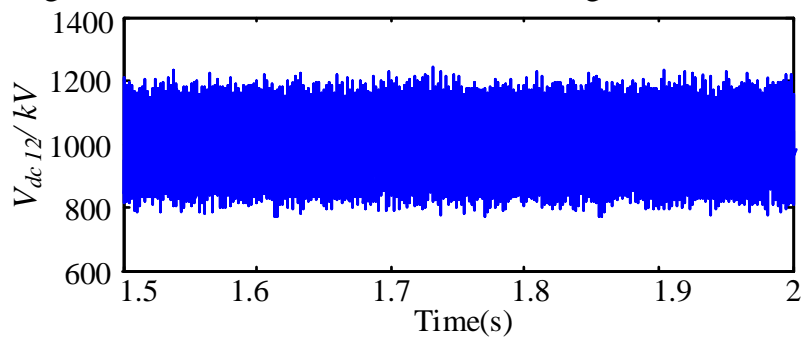

Fig. 11. The waveform of DC voltage added 20db noise.

In Fig. 11, the measurement of the original DC voltage signal will be affected by noise.

As pointed out by [23], the mean value of white noise is zero. To mitigate the impact of noise, the integral method is employed to modify the criterion:

$$
\int V_{L m n_{-} l(0)}=\int_{0}^{T_{w}} V_{L^{2} n_{-} l(0)} d t
$$

where $T_{w}$ is the time window for integral process. To guarantee the reactor voltage constantly rise during the integral process, $T_{w}$ is selected as $0.5 \mathrm{~ms}$ in this paper.

The waveforms of integration of voltage $V_{L 12 \_l}\left(\int V_{L 12 \_1}\right)$ without noise and with $20 \mathrm{db}$ noise are shown in Fig. 12. As can be seen, the integral method can be adopted to improve the robustness to noise.

$$
\int V_{L m n_{-} l(0)}=\int_{0}^{T_{w}} V_{L m n_{-} l(0)} d t
$$

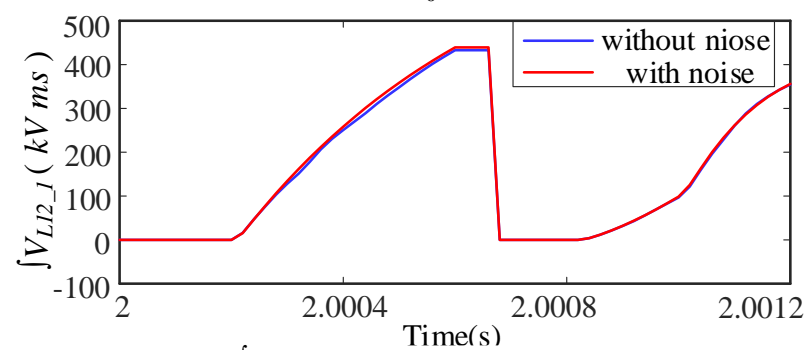

Fig. 12. Waveforms of $\int V_{L 12 \_}$without noise and with $20 \mathrm{db}$ noise.

The modified criterion for the selection of the faulted pole using the integral method is expressed as:

$$
\begin{cases}\int V_{\text {Lmn_o }}>\lambda_{\text {set }} & \Rightarrow P-P T G \text { faults } \\ -\lambda_{\text {set }}<\int V_{\text {Lmn_o }}<\lambda_{\text {set }} & \Rightarrow P T P \quad \text { faults } \\ \int V_{\text {Lmn_o }}<-\lambda_{\text {set }} & \Rightarrow N-P T G \text { faults }\end{cases}
$$

where $\lambda_{\text {set }}$ is the threshold for the faulted pole selection and the determination of $\lambda_{\text {set }}$ will be conducted in section V.A.

To determine the beginning time of the integral process, the rate of change of DC voltage (ROCOV) is employed as the fault start-up element. The subsequent protection will be activated when the following equation holds true:

$$
d V_{d c} / d t<D_{V d c}
$$

where $D_{V d c}$ is the setting threshold of the start-up element and the determination of $D_{V d c}$ will be conducted in section V.A.

\section{The Flow Chart of the Overall Protection Scheme}

Based on the above analysis, the overall protection scheme can be obtained, as shown in Fig. 13.

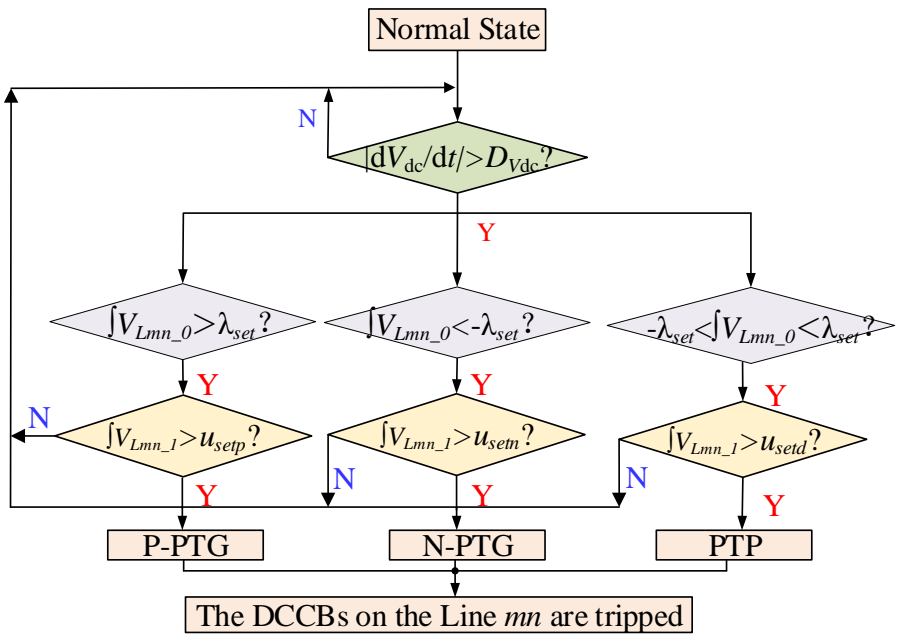

Fig. 13. The flow chart of the proposed protection method.

Once the criterion (18) holds true, the fault start-up element will be activated and the subsequent protection scheme will be conducted. In Fig. 13, $u_{\text {setp }(n)}$ and $u_{\text {setd }}$ represent the setting thresholds of $\int V_{L m n_{-} l}$ under PTG and PTP faults respectively. Considering that there exist different setting thresholds for fault detection under different fault types, such as $u_{\operatorname{setp}(n)}$ and $u_{\text {setd }}$, the faulted pole will be selected first. On detecting $\int V_{\text {Lmn_o }}>\lambda_{\text {set }}$ and $\int V_{\text {Lmn_l }}>u_{\text {setp }}$, an internal P-PTG fault is 
This paper is a post-print of a paper submitted to and accepted for publication in IEEE Journal of Emerging and Selected Topics in Power Electronics and is subject to Institution of Electrical and Electronic Engineering Copyright. The copy of record is available at IEEE Xplore Digital Library

identified. On detecting $\int V_{L m n \_o}<-\lambda_{\text {set }}$ and $\int V_{L m n_{-} l}>u_{\text {setn }}$, an internal N-PTG fault is identified. On detecting $-\lambda_{\text {set }}<\int V_{\text {Lmn_o }}<$ $\lambda_{\text {set }}$ and $\int V_{L m n_{-} l}>u_{\text {setd }}$, an internal PTP fault is identified.

\section{SIMULATION AND VERIFICATION}

In order to verify the feasibility and effectiveness of the proposed method, a $\pm 500 \mathrm{kV}$ four-terminal MMC based DC grid shown in Fig. 1 is built in PSCAD/EMTDC. The current-limiting reactor is selected as $0.15 \mathrm{H}$ [6]. The other converter parameters are listed in Table 4. MMC1 controls the DC link voltage while other converters control the transmitted power.

Table 4 Parameters of each converter station

\begin{tabular}{c||cccc}
\hline Converter & MMC1 & MMC2 & MMC3 & MMC4 \\
\hline arm inductance $/ \mathrm{mH}$ & 96 & 144 & 115 & 192 \\
sub-module capacitor $/ \mathrm{mF}$ & 15 & 10 & 12.5 & 8 \\
sub-module number / $N$ & 200 & 200 & 200 & 200 \\
rate power / MW & 3000 & 2000 & 2500 & 1500 \\
\hline
\end{tabular}

\section{A. Determination of Setting Value}

Taking the relay of CB12 as an example, the threshold setting calculation will be conducted as follows.

\section{1) Threshold Setting for Start-up Element}

To determine the beginning time of the integral process $\left(\int V_{L m n_{-} l}\right)$, the rate of change of DC voltage $\left(d V_{d c} / d t\right)$ is employed as the fault start-up element. The fault start-up element can be activated when $d V_{d c} d d t<D_{V d c}$. The principle to select the $D_{V d c}$ is as follows:

$D_{V d c}$ should be selected to avoid activation during normal operation and it should be activated during DC fault conditions. Thus, to cover all internal faults, $D_{V d c}$ should be larger than the observed maximum value of $d V_{d c} / d t$ during internal faults. However, to enable fast detection, the selection of $D_{V d c}$ should leave a margin so that the protection scheme can be activated as soon as possible.

Based on the above principle, taking DCCB 12 as an example, scan different DC bus faults and line faults along OHL12 and OHL 41. Then, the voltage derivatives $d V_{d c} d t$ under DC faults are obtained in Table 5.

In Table 5, the R-PTP and R-PTG represent the PTP fault with $200 \Omega$ fault resistance and PTG fault with $200 \Omega$ fault resistance respectively. As shown in Table 5, for internal faults, the maximum value of $d V_{d c} / d t$ is $-1200 \mathrm{kV} / \mathrm{ms}$. Based on the above principle, $D_{V d c}$ should not exceed $-1200 \mathrm{kV} / \mathrm{ms}$. Besides, to activate the following protection scheme as fast as possible, $D_{V d c}$ is selected as $-200 \mathrm{kV} / \mathrm{ms}$.

\section{2) Threshold Setting for Faulted Pole Selection}

According to (17), the positive coefficient $\lambda_{\text {set }}$ should satisfy the following requirements to select the faulted pole: For PTP faults, $\left|\int V_{L m n \_}\right|$should be much smaller than $\lambda_{\text {set }}$. In addition, $\int V_{\text {Lmn_o }}$ should be much larger than $\lambda_{\text {set }}$ for P-PTG faults but much smaller than $-\lambda_{\text {set }}$ for N-PTG faults, as illustrated in Fig. 14.

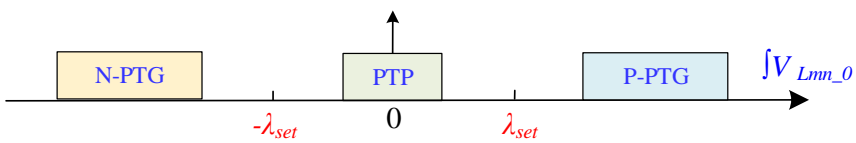

Fig. 14. The principle to select the positive coefficient $\lambda$.

Based on the above principle, taking DCCB12 as an example, scan different DC line PTP and P-PTG faults along OHL12 respectively. Then, $\int V L 12 \_0$ under different DC faults are obtained in Table 6.

\begin{tabular}{|c|c|c|c|c|c|c|c|c|c|c|c|c|}
\hline \multirow{2}{*}{ Faults } & \multicolumn{4}{|c|}{$F_{I}$} & \multicolumn{4}{|c|}{ The head of OHL14 } & \multicolumn{4}{|c|}{ The end of OHL14 } \\
\hline & PTP & R-PTP & PTG & R-PTG & PTP & R-PTP & PTG & R-PTG & PTP & R-PTP & PTG & R-PTG \\
\hline$d V_{d d} d d t(k V / m s)$ & -1117 & -612 & -210 & -170 & -2103 & -600 & -200 & -100 & -1174 & -121 & -68 & -30 \\
\hline \multirow{2}{*}{ Faults } & \multicolumn{4}{|c|}{ The head of OHL12 } & \multicolumn{4}{|c|}{ The end of OHL12 } & & & & \\
\hline & PTP & R-PTP & PTG & R-PTG & PTP & R-PTP & PTG & R-PTG & & & & \\
\hline$d V_{d d} d t(k V / m s)$ & -7000 & -5014 & -2543 & -1577 & -4044 & -3132 & -1899 & -1200 & & & & \\
\hline
\end{tabular}

Table 6 the simulation values of $\int V L 120$ under different DC faults

\begin{tabular}{|c|c|c|c|c|}
\hline \multirow{2}{*}{ Location } & \multicolumn{4}{|c|}{$\int V_{L 12 \_0}$} \\
\hline & Metallic PTP faults & PTP faults with $200 \Omega$ resistance & Metallic PTP faults & PTP faults with $200 \Omega$ resistance \\
\hline The head of OHL12 & -0.00353 & -0.00351 & 102 & 62 \\
\hline $1 / 4$ of OHL12 & -0.00384 & -0.00183 & 106 & 64 \\
\hline $3 / 4$ of OHL12 & 0.00752 & 0.00755 & 110 & 63 \\
\hline The end of OHL12 & 0.01085 & 0.01087 & 110 & 68 \\
\hline
\end{tabular}

As can be seen from Table $6,\left|\int V_{\text {Lmn }}\right|$ under PTP faults are very close to zero. In addition, $\int V_{L m n \_} o$ under P-PTG faults with $200 \Omega$ resistance are around $60 \mathrm{kV}^{*} \mathrm{~ms}$. Thus, $\lambda_{\text {set }}$ can be obtained: $\lambda_{\text {set }}=k_{\text {rel }} \times 60$. In this paper, $k_{\text {rel }}$ is selected as $1 / 3$. Finally, $\lambda_{\text {set }}$ can be calculated as $20 \mathrm{kV}^{*} \mathrm{~ms}$.

\section{3) Threshold Setting for Fault Detection}

$V_{\text {set }}$ should be smaller than the minimum value under internal faults but larger than the maximum value under external faults. For relay CB12, the maximum value under external faults can be obtained under $F_{2}$ fault. Applying metallic PTP and P-PTG faults at $F_{2}$ respectively, the simulation values of $\int V_{L 12_{2} l}$ are $239 k V^{*} m s$ (for PTP faults) and $45 k V^{*} m s$ (for P-PTG faults) respectively. Considering $200 \Omega$ resistance and a certain margin, $V_{\text {setd }}$ (for PTP faults) and $V_{\text {setn }(p)}$ (for P-PTG faults) are selected as $275 \mathrm{kV}^{*} \mathrm{~ms}$ and $68 \mathrm{kV} \mathrm{V}^{*} \mathrm{~ms}$.

\section{B. Simulation Analysis for Different Faults}

1) Simulation Analysis under PTP Faults

At 2.0s, a metallic PTP fault is applied at 25\% of OHL12 and the simulation waveforms are shown in Fig. 15.

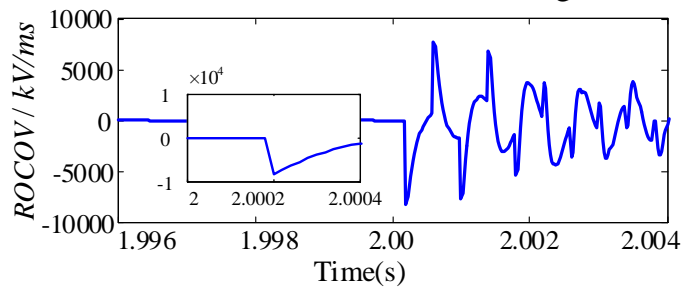

(a) ROCOV 
This paper is a post-print of a paper submitted to and accepted for publication in IEEE Journal of Emerging and Selected Topics in Power Electronics and is subject to Institution of Electrical and Electronic Engineering Copyright. The copy of record is available at IEEE Xplore Digital Library

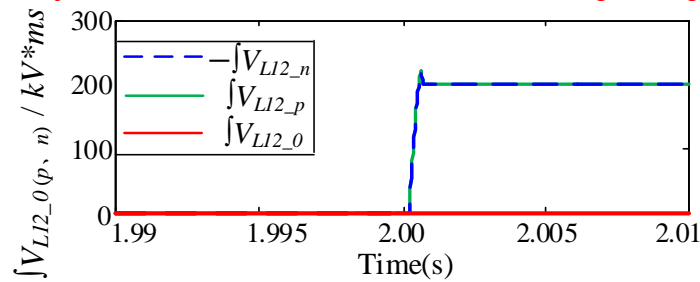

(b) Zero-mode and negative and positive reactor voltages

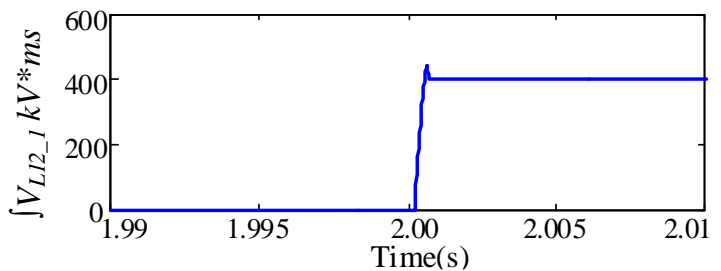

(c) Line-mode reactor voltage

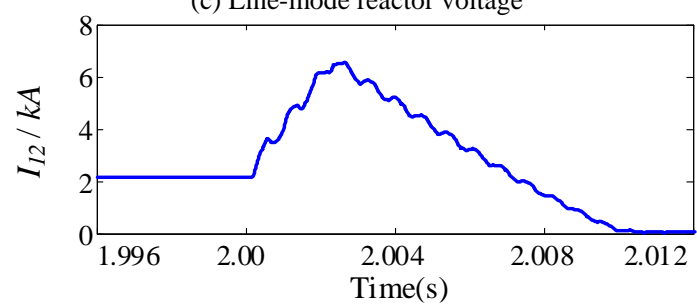

(d) Fault current

Fig. 15. Simulation waveforms of voltage and current under a metallic PTP fault.

As shown in Fig. 15 (a), the ROCOV is smaller than -200 $\mathrm{kV} / \mathrm{ms}$. Thus, the start-up element is activated. In Fig. 15 (b) and Fig. 15 (c), $-20 k V^{*} m s<\int V_{L 12_{-} 0}<20 k V^{*} m s$, and $\int V_{L 12 \_}>275 k V^{*} m s$. Hence, it is deemed to be an internal PTP fault. In Fig. 15 (d), the fault current $I_{12}$ rapidly rises to around $6 \mathrm{kA}$. Subsequent to trip of DCCB12, the current $I_{12}$ begins to decrease and decays to zero within $8 \mathrm{~ms}$.

\section{2) The Simulation Analysis under P-PTG Fault}

At 2.0s, a metallic P-PTG fault is applied in the middle of OHL12 and the simulation waveforms are shown in Fig. 16.

As shown in Fig. 16(a), the ROCOV is smaller than -200 $\mathrm{kV} / \mathrm{ms}$. Thus, the start-up element is activated. In Fig. 16(b) and Fig. 16(c), $\int V_{L 12 \_0}>20 \mathrm{kV}^{*} \mathrm{~ms}$ and $\int V_{L 12_{-} l}>68 \mathrm{kV}^{*} \mathrm{~ms}$. Hence, it is deemed to be an internal P-PTG fault. The fault current $I_{12}$ rises to around $3 \mathrm{kA}$. Subsequent to trip of DCCB12, $I_{12}$ begins to decrease and decays to zero within $6 \mathrm{~ms}$, as shown in Fig. 16(d).

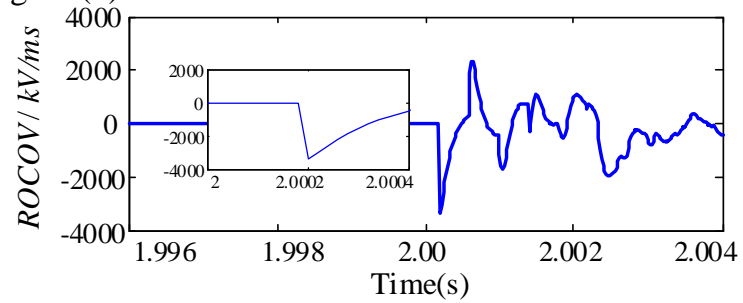

(a) ROCOV

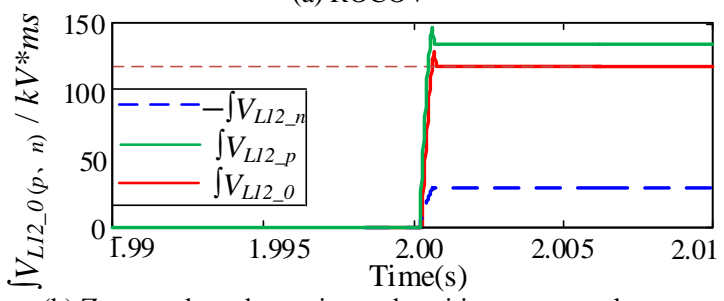

(b) Zero-mode and negative and positive reactor voltages

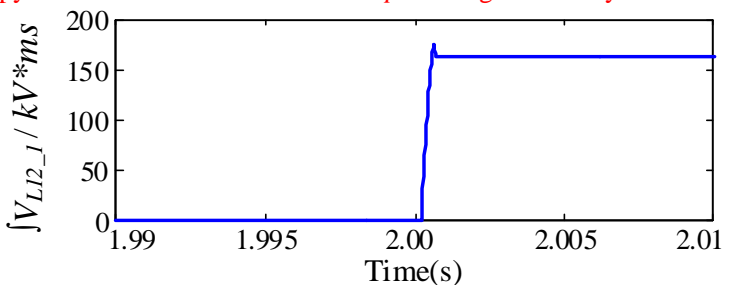

(c) Line-mode reactor voltage

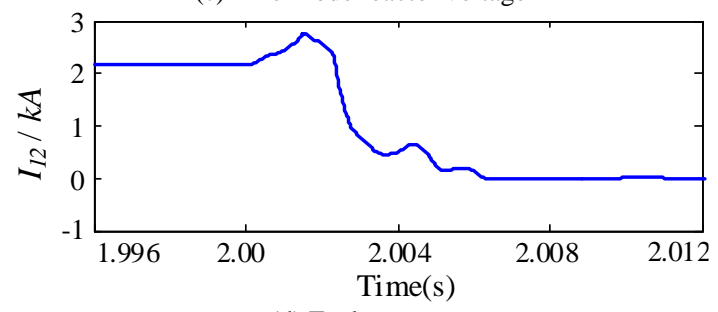

(d) Fault current

Fig. 16. Simulation waveforms of voltage and current under a metallic P-PTG fault.

\section{Influence of Fault Resistance}

To verify the influence of fault resistance on the proposed method, PTP and P-PTG faults with different locations and resistances are applied. Values of $\int V_{L 12_{-} l}$ are shown in Fig. 17.

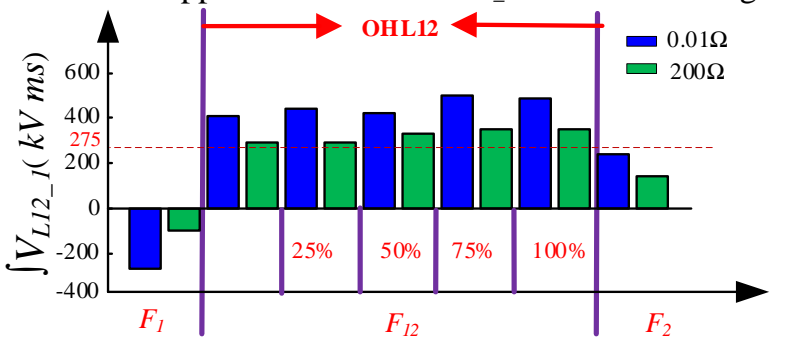

(a) PTP faults

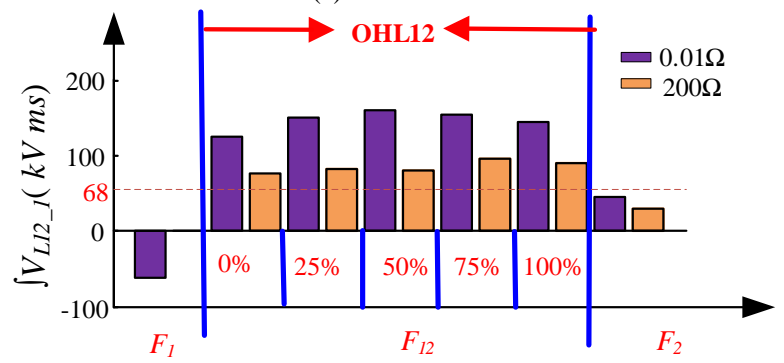

(b) PTG faults

Fig. 17. The values of $\int V L 12 \_1$ under faults with different resistances.

As shown in Fig. 17, $\int V_{L 12_{-} l}$ decreases with the increase of fault resistance. However, when the fault resistance is no more than $200 \Omega, \int V_{L 12_{-} I}$ under internal faults are always larger than the threshold while $\int V_{L 12_{2} l}$ under external faults are still smaller than it. Thus, the proposed method can identify faults with $200 \Omega$ resistance.

\section{Detection Time}

Traveling wave induced from fault point takes some time to arrive at the measurement position. Meanwhile, high-resistance faults require longer time to activate the start-up element and exceed the threshold for fault detection. Thus, a P-PTG fault with $200 \Omega$ resistance at the end of OHL12 is applied to obtain the longest detection time at $2.0 \mathrm{~s}$. The result is shown in Table 7 and the state of DCCB12 is shown Fig. 18 (" $l$ " represents the tripping of DCCBs). The simulation results demonstrate that the longest detection time 
This paper is a post-print of a paper submitted to and accepted for publication in IEEE Journal of Emerging and Selected Topics in Power Electronics and is subject to Institution of Electrical and Electronic Engineering Copyright. The copy of record is available at IEEE Xplore Digital Library

is less than $1.1 \mathrm{~ms}$. Thus, the scheme is fast for fault detection.

Table 7 The detection time of the different protection

\begin{tabular}{|c|c|c|}
\hline \multicolumn{2}{|r|}{ Parameter } & Value \\
\hline \multicolumn{2}{|r|}{ Fault resistance } & $200 \Omega$ \\
\hline \multicolumn{2}{|r|}{ Fault position } & at the end of OHL12 \\
\hline \multirow{2}{*}{ Start-up } & Propagation time of traveling-wave & $0.8 m s$ \\
\hline & Total delay for fault start-up element & $0.82 m s$ \\
\hline \multicolumn{2}{|r|}{ Total Detection Delay } & $1.04 \mathrm{~ms}$ \\
\hline
\end{tabular}

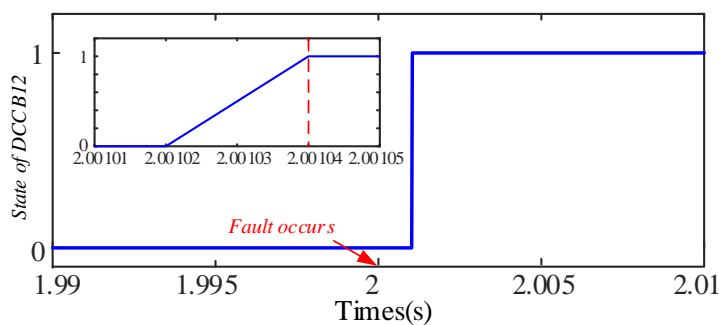

Fig. 18. The state of DCCB12 under P-PTG fault with $200 \Omega$ resistance at the end of OHL12.

\section{ROBUST ANALYSIS}

\section{A. Influence of Change of Operation Mode}

Further studies are conducted to test the impact of change of operation mode on the proposed protection strategy. At $1.5 \mathrm{~s}$, active power of each converter reverses. At 2.0s, the system power recovers to steady state, as shown in Fig. 19(a). At 4s, a metallic PTP fault is applied in the middle of OHL12.

In Fig. 19(b), although power reversal causes a large power fluctuation, the fluctuation of DC line voltage is small and the start-up element is not activated. After power reversal, a PTP fault occurs in the middle of OHL12. The DC voltage drops rapidly and the start-up element is activated. Since $\int V_{L 12_{2} l}$ is larger than $275 \mathrm{kV}^{*} \mathrm{~ms}$, the fault can be identified to be internal correctly, as shown in Fig. 19 (c).

To be concluded, power reversal has no influence on the proposed scheme.

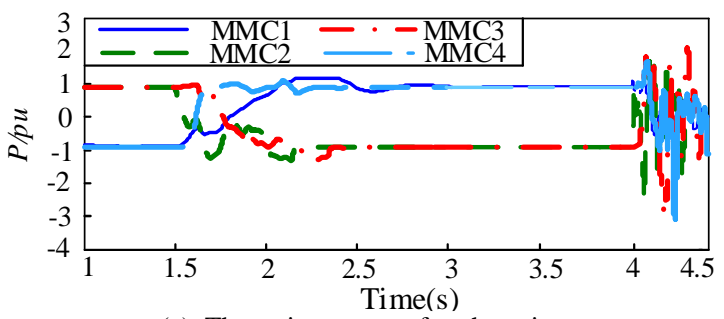

(a) The active power of each station

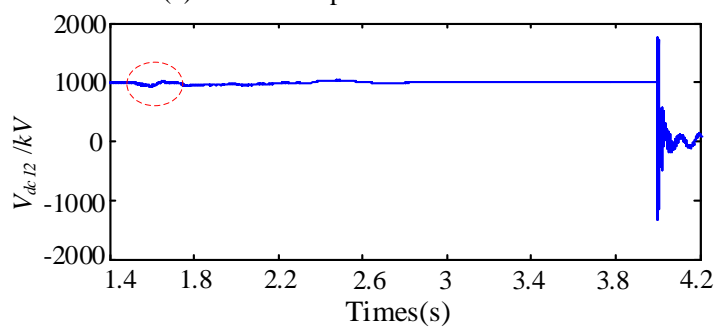

(b) The DC line voltage $V_{d c 12}$

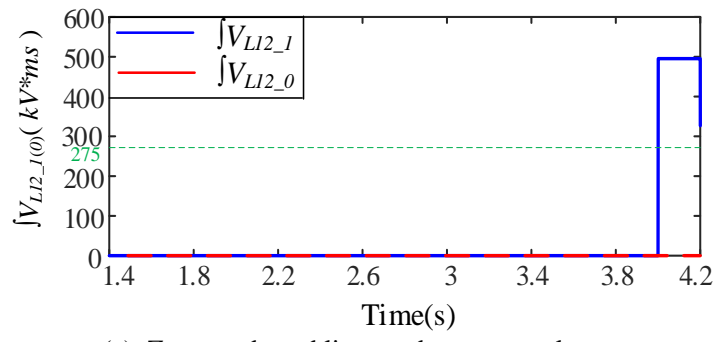

(c) Zero-mode and line-mode reactor voltages

Fig. 19. The simulation waveforms under power reversal.

\section{B. Influence of Noise}

To test the influence of noise, a 10db white noise is added into the measured signals and a metallic PTP fault is applied at $F_{2}$. The waveform $\int V_{L 12_{-} l}$ is shown in Fig. 20.

As can be shown, $\int V_{L 12_{-} I}$ is always smaller than $275 \mathrm{kV} * m s$. Thus, the fault is identified to be external.

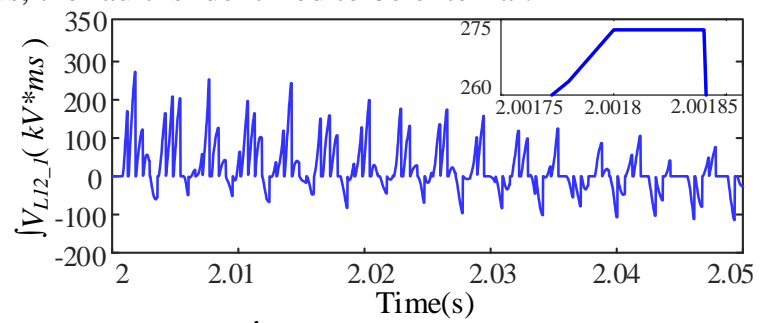

Fig. 20. The waveform of $\int V_{L 12 \_}$when the SNR is $10 \mathrm{db}$.

More simulation cases with $10 \mathrm{db}, 20 \mathrm{db}$, and $30 \mathrm{db}$ noise are conducted and the simulation results are shown in Table 8. To be concluded, the protection scheme has strong anti-noise ability and can achieve fault detection under $10 \mathrm{db}$ noise disturbance.

Table 8 Influence of noise with different SNR on the proposed protection

\begin{tabular}{c||c}
\hline SNR $(\mathrm{db})$ & The situation of protection \\
\hline 10 & No action \\
20 & No action \\
30 & No action \\
\hline
\end{tabular}

\section{Influence of DCCB Operation}

At 2 s, a metallic PTP fault is applied in the middle of OHL14, and tripping orders are issued to DCCB14 and DCCB41 at 2.0005s. To test the influence of DCCB14 and DCCB41 operation on relay $\mathrm{CB} 12, \int V_{L 12_{-} l}$ is measured, as shown in Fig. 21.

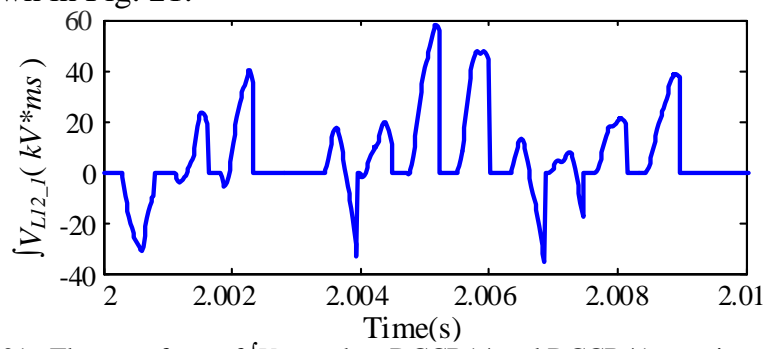

Fig. 21. The waveform of $\int V_{L I 2_{-} I}$ when DCCB 14 and DCCB41 are tripped.

During the trip of DCCB14 and DCCB41, $\int V_{L 12 \_l}$ is always smaller than $275 \mathrm{kV}^{*} \mathrm{~ms}$, which will not bring about the false operation of relay CB12. Thus, DCCB operation has no impact on the relay $\mathrm{CB} 12$.

\section{Influence of the Size of CLR}

Voltage of C LR is proportional to the size of CLR. Thus, small CLR will lead to difficulty of threshold setting. Meanwhile, the smaller the CLR, the less obvious the 
This paper is a post-print of a paper submitted to and accepted for publication in IEEE Journal of Emerging and Selected Topics in Power Electronics and is subject to Institution of Electrical and Electronic Engineering Copyright. The copy of record is available at IEEE Xplore Digital Library

boundary characteristics. For further study on influence of the size of CLR, reactors vary from the $100 \mathrm{mH}$ to $200 \mathrm{mH}$, and internal PTP faults with $200 \Omega$ resistance and external metallic PTP faults are applied respectively. Simulation results are shown in Fig. 22, where the fault position -0.25 represents the $F_{2}$ fault.

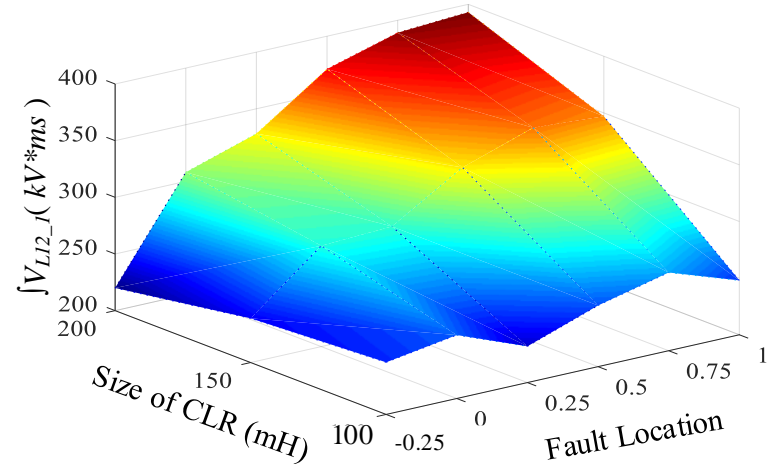

Fig. 22. The value of $\int V_{L / 2} I$ under different faults with different reactors.

In Fig. 22, when CLR is $100 \mathrm{mH}$, the difference of $\int V_{L 12} I$ between external and internal faults is small, leading to the decreased detection accuracy to fault resistance. With the increase of CLR size, difference of $\int V_{L 12_{-} I}$ becomes more obvious and the robustness of the protection scheme enhances.

\section{E. Response to AC Faults}

To test the impacts of AC faults on DC fault protection, a metallic three-phase AC fault $F_{A C l}$ is applied at the secondary side of power transformers close to AC system S1 at 2.0s, as shown in Fig. 23.

In Fig. 23(a) and (b), the DC line voltage $V_{d c 12}$ drops slowly during initial stage of AC fault and the rate of change of DC voltage $d V_{d c 12} / d t$ is less than $-200 \mathrm{kV} / \mathrm{ms}$ at $2.012 \mathrm{~s}$, thereby triggering the fault start-up element. The integral of the change of DC line voltage $\left(\int\left|\Delta V_{d c 12}\right|\right)$ under this circumstance is 186 $k V^{*} m s$, which is larger than that under the PTG DC fault with $200 \Omega$ resistance at the end of OHL12. The specific comparison is presented in Fig. 23(c) and Fig. 24 (b), which demonstrates that $\int\left|\Delta V_{d c 12}\right|$ cannot identify the internal DC faults and $\mathrm{AC}$ faults.

In addition, in Fig. 23(a), the minimum value of DC line voltage $V_{d c 12}$ is $352 \mathrm{kV}$ under $\mathrm{AC}$ fault while it is larger than $400 \mathrm{kV}$ under DC fault, as shown in Fig. 24 (a). Thus, the low-voltage criterion is also sensitive to AC faults.

However, the measured $\int V_{L 12 \_l}$ under $\mathrm{AC}$ fault $F_{A C l}$ is negative, as shown in Fig. 23(b). Hence, the AC fault $F_{A C l}$ will be deemed to be external and it will not lead to the false operation of the proposed method.

To further verify the robustness of the proposed method to AC faults, a metallic three-phase AC fault $F_{A C 2}$ is tested at AC system S2. When the AC short circuit fault $F_{A C 2}$ occurs, the DC line voltage will have a small fluctuation and not activate the start-up element. Thus, the proposed protection scheme is not affected by AC faults.

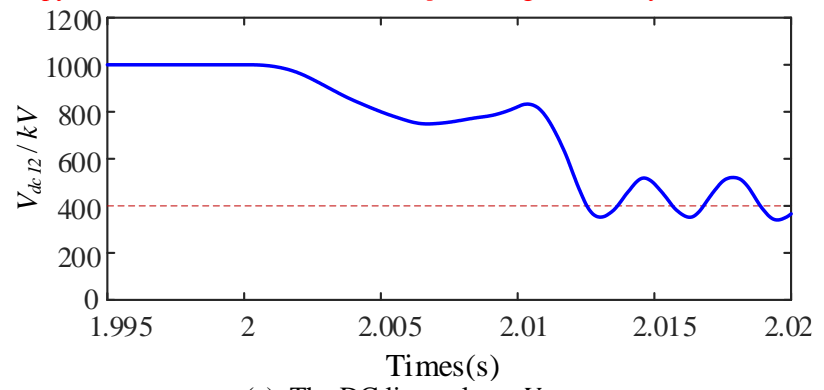

(a) The DC line voltage $V_{d c 12}$

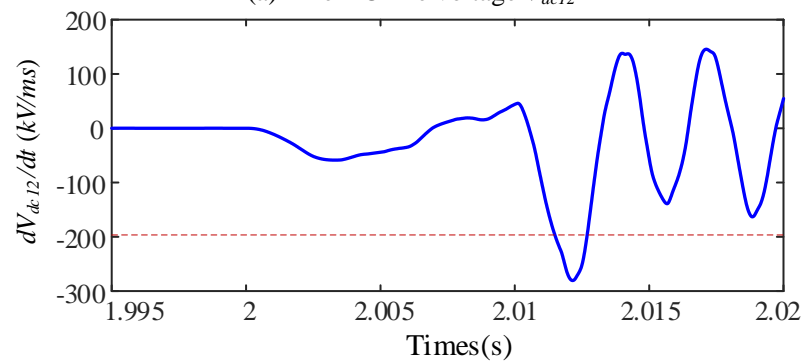

(b) The rate of change of DC voltage $d V_{d c 12} / d t$

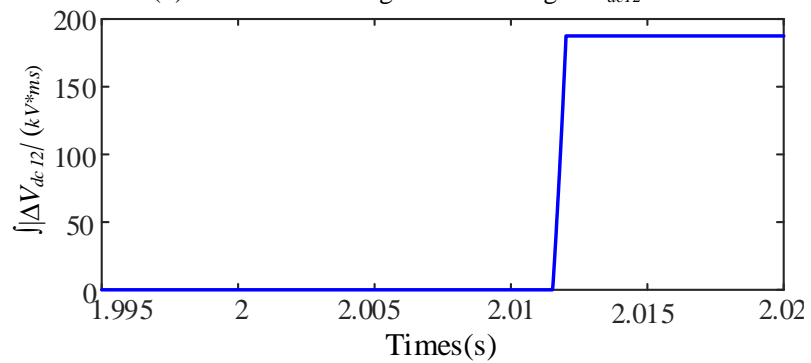

(c) The integral of the change of DC line voltage $\left(\int\left|\Delta V_{d c 12}\right|\right)$

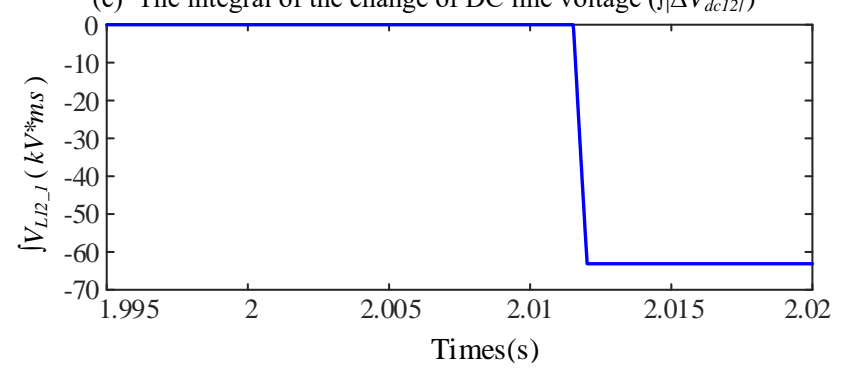

(d) The integral of the line-mode reactor voltage

Fig. 23. The simulation waveforms under a metallic AC fault at S1.

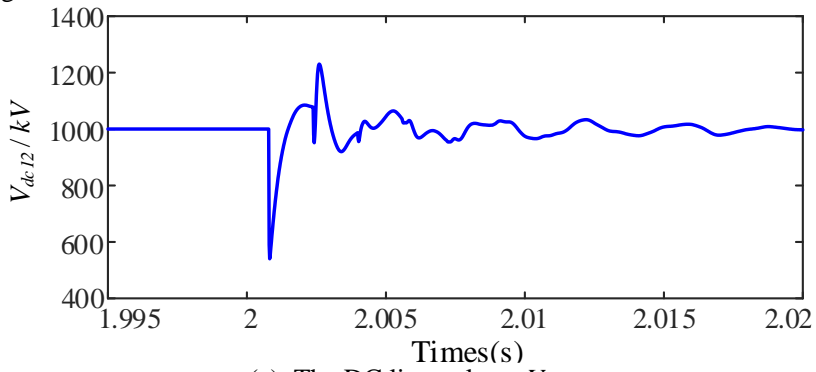

(a) The DC line voltage $V_{d c l 2}$

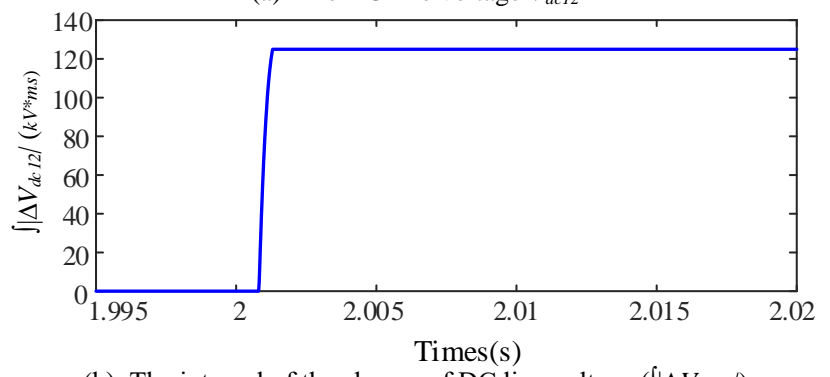

(b) The integral of the change of DC line voltage $\left(\int\left|\Delta V_{d c 12}\right|\right)$ 
This paper is a post-print of a paper submitted to and accepted for publication in IEEE Journal of Emerging and Selected Topics in Power Electronics and is subject to Institution of Electrical and Electronic Engineering Copyright. The copy of record is available at IEEE Xplore Digital Library

Fig. 24. The simulation waveforms under a PTG fault with $200 \Omega$ resistance at the end of OHL12.

\section{F. Comparison with Other Protection Methods}

1) The DC Reactor Voltage Change Rate (RVCR) Method in [12]

The topology for the simulation is shown in Fig. 1 and the specific parameter is shown in Table 4. Taking DCCB 12 as an example, apply a P-PTG fault with $200 \Omega$ resistance in the middle of OHL12 $\left(F_{12}\right)$ at $2 \mathrm{~s}$. The measured RVCR is 2000kV/ms, as shown in Fig. 25 (a). Apply a metallic P-PTG fault at $F_{2}$ at $2 \mathrm{~s}$. The measured RVCR is $2284 \mathrm{kV} / \mathrm{ms}$, as shown in Fig. 25 (b). It can be seen that the RVCR during an external fault $F_{2}$ is higher than that during an internal fault $\left(F_{12}\right)$. Thus, the RVCR cannot be applied to the P-PTG faults.

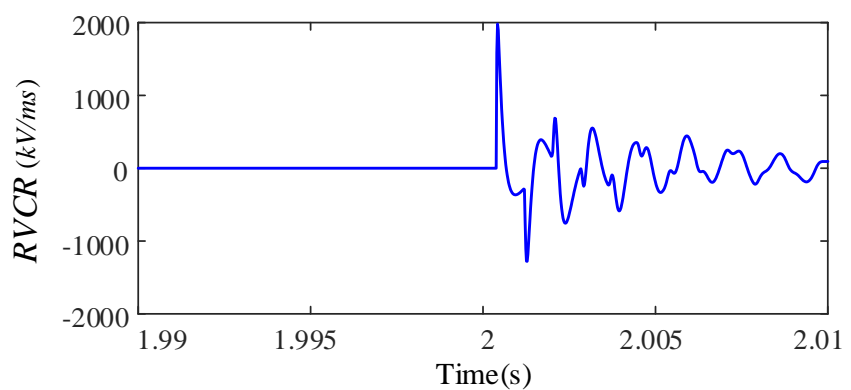

(a) RVCR during internal fault $\left(F_{12}\right)$

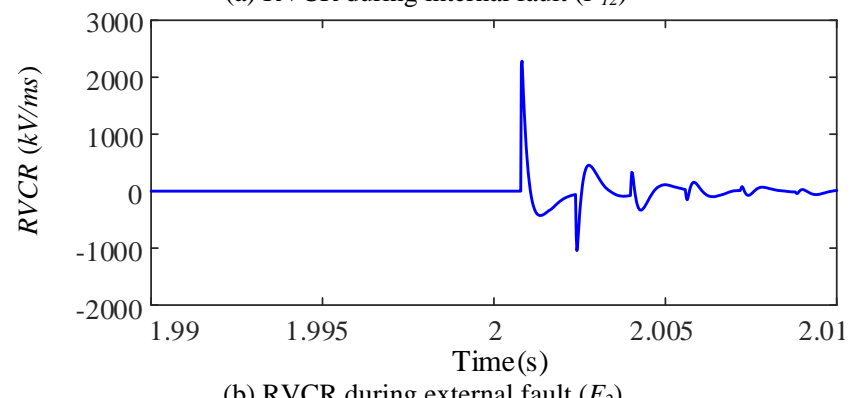

(b) RVCR during external fault $\left(F_{2}\right)$

Fig. 25. Simulation results using RVCR method.

\section{2) The DC Reactor Voltage Method in [13]}

Taking DCCB 12 as an example, apply a PTG fault with $100 \Omega$ resistance at the head of OHL12 $\left(F_{12}\right)$ at $2 \mathrm{~s}$. The measured reactor voltage of faulted pole (RVOFP) is smaller than $300 \mathrm{kV}$, as shown in Fig. 26 (a). Apply a metallic PTP fault at $F_{2}$ at 2 s. The measured RVOFP exceeds $300 \mathrm{kV}$, as shown in Fig. 26 (b). It can be seen the RVOFP during an external fault $F_{2}$ is higher than that during an internal fault $\left(F_{12}\right)$. Thus, using the RVOFP criterion, the internal faults with high fault resistance cannot be identified.

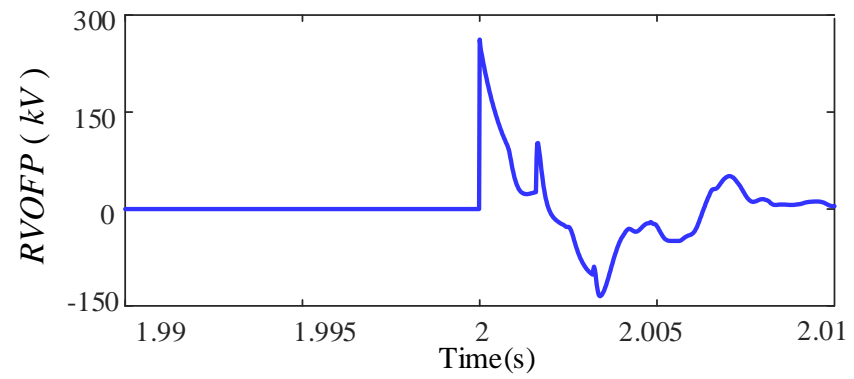

(a) RVOFP during internal fault $\left(F_{12}\right)$

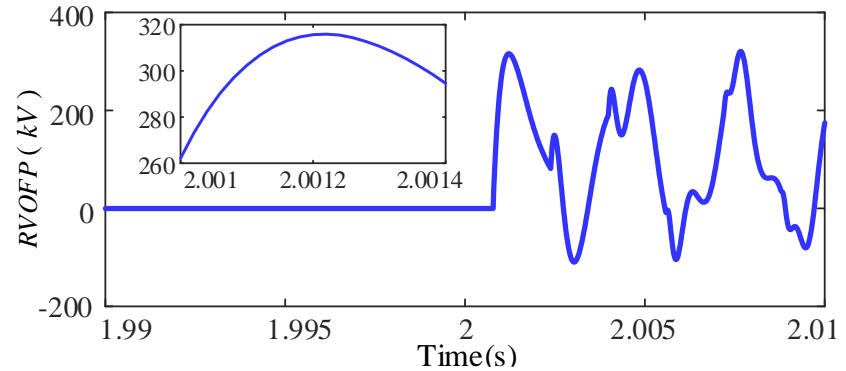

(b) RVOFP during external fault $\left(F_{2}\right)$

Fig. 26. Simulation results using RVCR method.

\section{3) The Rate of Change of Voltage (ROCOV) Method in [9]}

Taking DCCB 12 as an example, applying a PTG fault with $200 \Omega$ resistance at the head of OHL12 $\left(F_{12}\right)$ and a metallic PTP fault at $F_{2}$ at 2 s respectively, the measured ROCOVs are shown in Fig. 27.

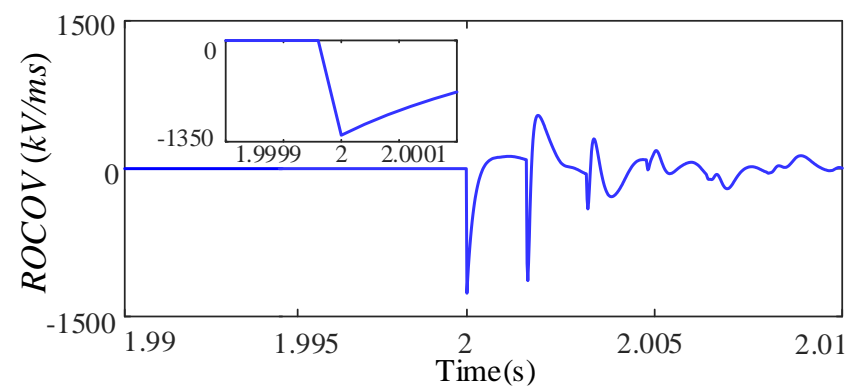

(a) ROCOV during internal fault $\left(F_{12}\right)$

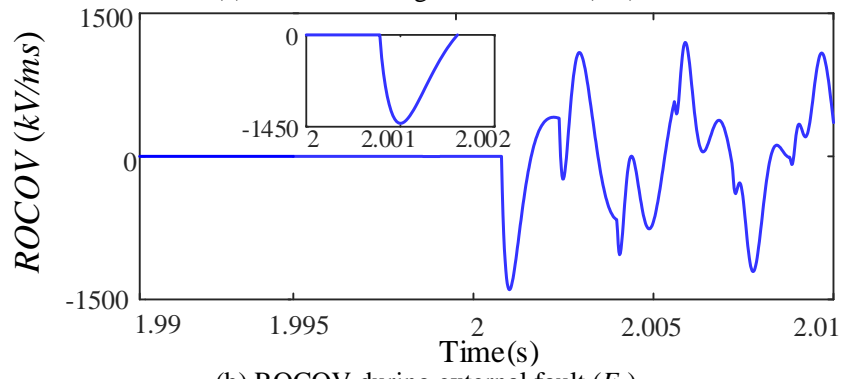

(b) ROCOV during external fault $\left(F_{2}\right)$

Fig. 27. Simulation results using ROCOV with different fault resistances.

It can be seen that measured ROCOV at $F_{12}$ is larger than that at $F_{2}$, which demonstrates that the ROCOV based method cannot work under high fault resistance.

Applying a metallic P-PTG fault at head of OHL12 $\left(F_{12}\right)$ and a metallic PTP fault with $20 \mathrm{db}$ noise at $F_{2}$ respectively, the measured ROCOVs are shown in Fig. 28. It can be seen that measured ROCOV at $F_{12}$ is larger than that at $F_{2}$, which demonstrates that the ROCOV based method is vulnerable to noise.

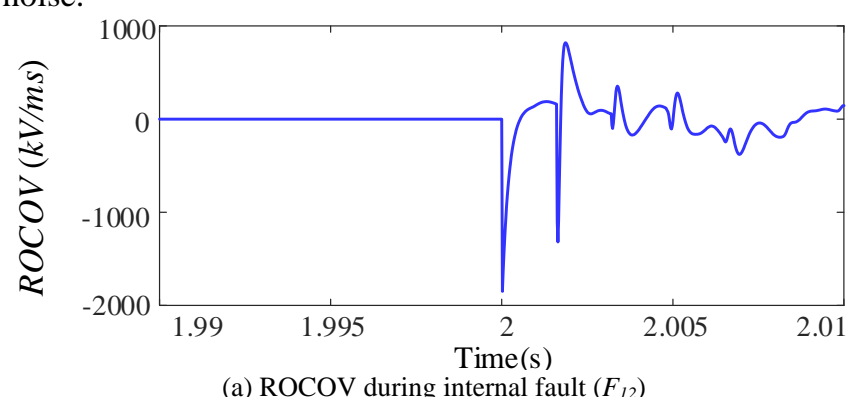

(a) ROCOV during internal fault $\left(F_{12}\right)$ 
This paper is a post-print of a paper submitted to and accepted for publication in IEEE Journal of Emerging and Selected Topics in Power Electronics and is subject to Institution of Electrical and Electronic Engineering Copyright. The copy of record is available at IEEE Xplore Digital Library

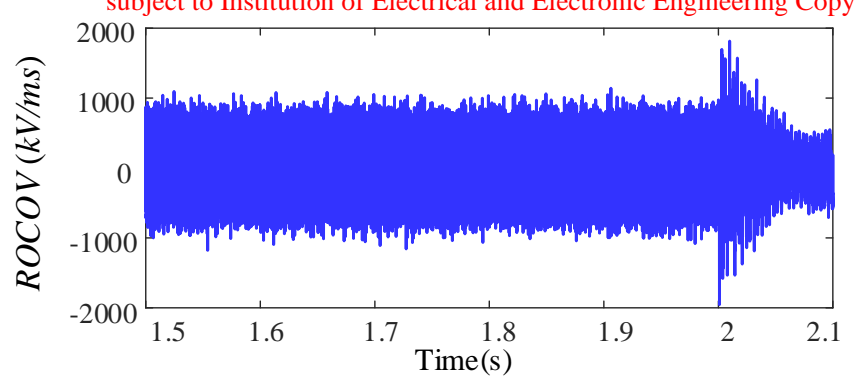

(b) ROCOV during external fault $\left(F_{2}\right)$

Fig. 28. Simulation results using ROCOV with noise.

\section{CONCLUSION}

A fast and selective protection scheme based on modal-domain analysis for overhead MMC based DC grids is proposed in this paper. Using the modal-domain analysis, the dependency of positive and negative poles of overhead lines is decoupled. From the theoretical analysis and simulations, it can be concluded that,

1) The PTG and PTP fault analysis under modal-domain are conducted respectively, which provides the theoretical basis for the design of protection algorithm.

2) The derivative of DC line voltage $\left(d V_{d c} / d t\right)$ is adopted as the start-up element. Then, the zero-mode reactor voltage $\left(\int V_{L 12 \_0}\right)$ is employed to select the faulted pole. The line-mode reactor voltage $\left(\int V_{L 12 \_}\right)$is employed to identify the internal and external faults.

3) The proposed method can identify faults with fault resistance as high as $200 \Omega$ and it is immune to noise with $10 \mathrm{~dB}$. By only using local measurements, the proposed protection scheme is fast, no more than $1.1 \mathrm{~ms}$. In addition, the method is not affected by DCCB interruptions, operating conditions and AC faults. Quantities of simulation results demonstrate that the smaller current-limiting reactor will reduce the sensitivity to fault resistance and the protection can work well when the CLR is larger than $100 \mathrm{mH}$.

4) In comparison with similar schemes, such as RVCR, RVOFP and ROCOV, the proposed method has advantages over the capability of the faulted pole selection, the robustness to high-resistance and noise disturbance.

\section{REFERENCES}

[1] W. Xiang, R. Yang, C. Lin, et al., "A Cascaded Converter Interfacing Long Distance HVDC and Back-to-Back HVDC Systems," IEEE Journal of Emerging and Selected Topics in Power Electron., early access, doi: 10.1109/JESTPE.2019.2913915.

[2] X. Li, Q. Song, W. Liu, et al., "Experiment on DC-fault ride through of MMC using a half-voltage clamp submodule," IEEE Journal of Emerging and Selected Topics in Power Electron., vol. 6, no. 3, pp. 1273-1279, Sept. 2018.

[3] W. Xiang, W. Lin, T. An, et al, "Equivalent Electromagnetic Transient Simulation Model and Fast Recovery Control of Overhead VSC-HVDC Based on SB-MMC," IEEE Trans. Power Del., vol. 32, no. 2, pp. 778-788, Apr. 2017.

[4] T. An, G. Tang, W. Wang, "Research and application on multi-terminal and DC grids based on VSC-HVDC technology in China," IET High Voltage, vol. 2, no. 1, pp. 1-10, Jun. 2017.

[5] G. Liu, F. Xu, Z. Xu, et al, "Assembly HVDC breaker for HVDC grids with modular multilevel converters," IEEE Trans. Power Electron., vol. 32, no. 2, pp. 931-941, Feb. 2017.

[6] M. Zhou, W. Xiang, W. Zuo, W. Lin, J. Wen, "A novel HVDC circuit breaker for HVDC application," Int. J. Elect. Power Energy Syst., Vol. 109, pp. 685-695, 2019.

[7] W. Xiang, S. Yang, L. Xu, et al, “A transient voltage based DC fault line protection scheme for MMC based DC grid embedding DC breakers," IEEE Trans. Power Del., vol. 34, no. 1, pp. 334-345, Feb. 2019.

[8] N. Geddada, Y. M. Yeap, A. Ukil, "Experimental Validation of Fault Identification in VSC-Based DC Grid System," IEEE Trans. Ind. Electron., vol. 65, no. 6, pp. 4799-4809, June 2018.

[9] J. Sneath, A. Rajapakse, "Fault detection and interruption in an earthed HVDC grid using ROCOV and hybrid DC breakers," IEEE Trans. Power Del., vol.31, no.3, pp. 973-981, Jun. 2016.

[10] Q. Huang, G. Zou, X. Wei, et al., "A non-unit line protection scheme for MMC-based multi-terminal HVDC grid," Int. J. Elect. Power Energy Syst., vol. 107, pp. 1-9, 2019.

[11] Q. Yang, S. L. Blond, R. Aggarwal, et al, "New ANN method for multi-terminal HVDC protection relaying," Electr. Power Syst. Research, vol. 148, pp. 192-201, 2017.

[12] R. Li, L. Xu, L. Yao, "DC fault detection and location in meshed multi-terminal HVDC systems based on DC reactor voltage change rate," IEEE Trans. Power Del., vol.32, no.3, pp. 1516-1626, Jun. 2017.

[13] C. Li, A. M. Gole, C. Zhao, "A fast DC fault detection method using DC reactor voltages in HVdc Grids," IEEE Trans. Power Del., vol. 33, no. 5, pp. 2254-2264, Oct. 2018.

[14] W. Leterme, S. Pirooz Azad, D. Van Hertem, "HVDC grid protection algorithm design in phase and modal-domains," IET Renewable Power Gener., vol. 12, no. 13, pp. 1538-1546, Sept. 2018.

[15] L. Tang, X. Dong, S. Shi, et al., "A high-speed protection scheme for the DC transmission line of a MMC-HVDC grid," Elect. Power Syst. Research, vol. 168, pp. 81-91, 2019.

[16] M. Kong, X. Pei, H. Pang, et al, "A lifting wavelet-based protection strategy against DC line faults for Zhangbei HVDC Grid in China," $19^{\text {th }}$ European Conf. on Power Electron. and Applica. (EPE'17 ECCE Europe), Warsaw, Poland, Sept. 2017, pp. 1-11.

[17] E. Kontos, R. T. Pinto, S. Rodrigue, et al, "Impact of HVDC transmission system topology on multiterminal DC network faults," IEEE Trans. Power Del., vol. 30, no. 2, pp.844-852, Apr. 2015.

[18] J. Yang, J. E. Fletcher, J. O. Reilly, "Short-circuit and ground fault analyses and location in VSC-based DC network cables," IEEE Trans. Ind. Electron., vol. 59, no. 10, pp. 3827-3837, Oct. 2012.

[19] C. Li, C. Zhao, J. Xu, et al, "A pole-to-pole short-circuit fault current calculation method for DC grids," IEEE Trans. Power Syst., vol. 32, no. 6, pp. 4943-4953, Nov. 2017.

[20] T. Wang, G. Song, L. Wu, et al., "Novel reclosure scheme of MMC-HVDC system based on characteristic signal injection," The Journal of Engineering, vol. 2019, no. 16, pp. 1153-1157, Mar. 2019.

[21] H. Li, Z. He, J. Yang, et al, "Switching overvoltage analysis for modular multilevel converters," High Voltage, vol. 43, no. 4, pp. 1144-1151, Apr. 2017.

[22] E. D. Kimbark, "Transient overvoltages caused by monopolar ground fault on bipolar DC line: theory and simulation," IEEE Trans. Power Appar. Syst., vol. 89, no. 4, pp. 584-592, Apr. 1970.

[23] J. Zhang, C. Y. Chung and L. Guan, "Noise Effect and Noise-Assisted Ensemble Regression in Power System Online Sensitivity Identification," IEEE Trans. Ind. Informat., vol. 13, no. 5, pp. 2302-2310, Oct. 2017.

\section{BIOGRAPHIES}

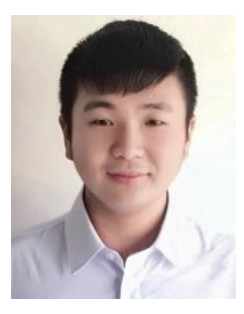

Saizhao Yang obtained his B.E. degree in electrical engineering from Huazhong University of Science and Technology (HUST), China, in 2018. He is currently pursuing his $\mathrm{PhD}$ degree at HUST. His research interests include dc fault protection of MMC-HVDC and de grids.

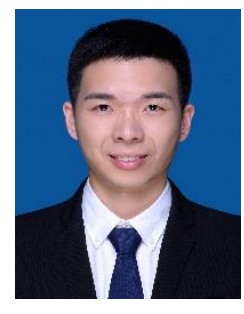

Wang Xiang (S'16-M'17) received his B.Eng. and $\mathrm{PhD}$ degrees both in electrical engineering from Huazhong University of Science and Technology (HUST), China in 2012 and 2017 respectively. He was a visiting student at the University of Aberdeen and the University of Strathclyde in 2014 and 2016 respectively. He was a research fellow at HUST in 2017 and 2018. Currently, he is a research associate with the University of Strathclyde. His main research interests include MMC-HVDC, high power dc/dc 
This paper is a post-print of a paper submitted to and accepted for publication in IEEE Journal of Emerging and Selected Topics in Power Electronics and is subject to Institution of Electrical and Electronic Engineering Copyright. The copy of record is available at IEEE Xplore Digital Library converters and dc grids.

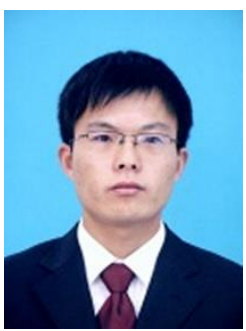

Rui Li received the M.S. and Ph.D degrees in electrical engineering from Harbin Institute of Technology, Harbin, China, in 2008 and 2013, respectively. $\mathrm{He}$ is a researcher with University of Strathclyde in Glasgow, UK, since 2013. His research interests include HVDC transmision system, grid integration of renewable power, power electronic converters, and energy conversion.

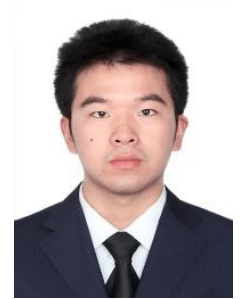

Xiaojun Lu (M'19) received his B.Eng and Ph.D degree both in electrical engineering from Huazhong University of Science and Technology (HUST), Wuhan, China in 2013 and 2018, respectively. He is currently a post-doctor at HUST. His main research interests include modeling and stability analysis of VSC/MMC-HVDC and DC grids.

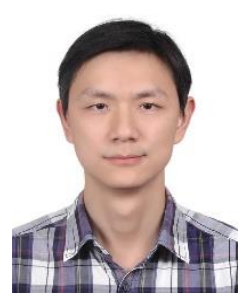

Wenping Zuo received the B.S. degree and Ph.D degree in electrical engineering from Huazhong University of Science and Technology (HUST), Wuhan, China, in 2009 and 2017, respectively. Currently he is a Post-Doctoral Research Fellow with HUST. His research interests include DC grid key equipment, energy storage, and renewable energy integration.

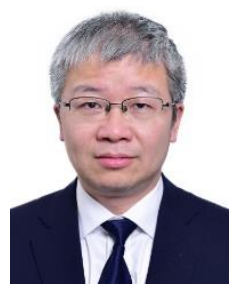

Jinyu Wen (M'10) received his B.Eng. and Ph.D. degrees all in electrical engineering from Huazhong University of Science and Technology (HUST), Wuhan, China, in 1992 and 1998, respectively. He was a visiting student from 1996 to 1997 and research fellow from 2002 to 2003 all at the University of Liverpool, $\mathrm{UK}$, and a senior visiting researcher at the University of Texas at Arlington, USA in 2010. From 1998 to 2002 he was a director engineer in XJ Electric Co. Ltd. in China. In 2003 he joined the HUST and now is a Professor at HUST. His current research interests include renewable energy integration, energy storage application, DC grid, and power system operation and control. 